\title{
Geomorphological significance of Ontario Lacus on Titan: Integrated interpretation of Cassini VIMS, ISS and RADAR data and comparison with the Etosha Pan (Namibia)
}

\author{
T. Cornet ${ }^{\mathrm{a}, 1}$, O. Bourgeois ${ }^{\mathrm{a}}$, S. Le Mouélic ${ }^{\mathrm{a}}$, S. Rodriguez ${ }^{\mathrm{b}}$, T. Lopez Gonzalez ${ }^{\mathrm{c}}$, C. Sotin ${ }^{\mathrm{a}, \mathrm{d}}$, G. Tobie ${ }^{\mathrm{a}}$, C. Fleurant ${ }^{\mathrm{e}}$, J.W. Barnes ${ }^{\mathrm{f}}$, \\ R.H. Brown ${ }^{\mathrm{g}}$, K.H. Baines ${ }^{\mathrm{d}}$, B.J. Buratti ${ }^{\mathrm{d}}$, R.N. Clark ${ }^{\mathrm{h}}$, P.D. Nicholson ${ }^{\mathrm{i}}$ \\ ${ }^{a}$ Laboratoire de Planétologie et Géodynamique de Nantes, UMR 6112, CNRS, Université de Nantes, Faculté des Sciences et Techniques, 2 rue de la Houssinière, \\ BP92208, 44322 Nantes Cedex 3, France. \\ ${ }^{b}$ Laboratoire AIM, Centre d'étude de Saclay, IRFU/Sap, Centre de l'Orme des Merisiers, bât. 709, 91191 Gif/Yvette Cedex, France. \\ ${ }^{c}$ Observatoire Midi-Pyrénées, UMR 5277, CNRS, 14 av. Edouard Belin, 31400 Toulouse, France. \\ ${ }^{d}$ Jet Propulsion Laboratory, California Institute of Technology, 4800 Oak Grove Drive, Pasadena, CA 91109, USA \\ ${ }^{e}$ Agrocampus Ouest Centre d'Angers - Institut National d'Horticulture et de Paysage, 2 rue André Le Nôtre, 49045 Angers Cedex 01, France. \\ ${ }^{f}$ Department of Physics, University of Idaho, Engineering-Physics Building, Moscow, ID 83844, USA. \\ ${ }^{g}$ Department of Planetary Sciences, University of Arizona, Tucson, AZ 85721, USA. \\ ${ }^{h}$ United States Geological Survey, Denver, CO 80225, USA. \\ ${ }^{i}$ Department of Astronomy, Cornell University, Ithaca, NY 14853, USA.
}

\begin{abstract}
Ontario Lacus is the largest lake of the whole southern hemisphere of Titan, Saturn's major moon. It has been imaged twice by each of the Cassini imaging systems (Imaging Science Subsystem (ISS) in 2004 and 2005, Visual and Infrared Mapping Spectrometer (VIMS) in 2007 and 2009 and RADAR in 2009 and 2010). We compile a geomorphological map and derive a "hydrogeological" interpretation of Ontario Lacus, based on a joint analysis of ISS, VIMS and RADAR SAR datasets, along with the T49 altimetric profile acquired in December 2008. The morphologies observed on Ontario Lacus are compared to landforms of a semi-arid terrestrial analog, which resembles Titan's lakes: the Etosha Pan, located in the Owambo Basin (Namibia). The Etosha Pan is a flat-floored depression formed by dissolution, under semi-arid conditions, of a surface evaporitic layer (calcretes) controlled by groundwater vertical motions. We infer that Ontario Lacus is an extremely flat and shallow depression lying in an alluvial plain surrounded by small mountain ranges under climatic conditions similar to those of terrestrial semi-arid regions. Channels are seen in the southern part of Ontario Lacus in VIMS and RADAR data, acquired at a 2-years time interval. Their constancy in location with time implies that the southern portion of the depression is probably not fully covered by a liquid layer at the time of the observations, and that they most probably run on the floor of the depression. A shallow layer of surface liquids, corresponding to the darkest portions of the RADAR images, would thus cover about $53 \%$ of the surface area of the depression, of which almost $70 \%$ is located in its northern part. These liquid-covered parts of the depression, where liquid ethane was previously identified, are interpreted as topographic lows where the "alkanofer" raises above the depression floor. The rest of the depression, and mostly its southern part, is interpreted as a flat and smooth exposed floor, likely composed of a thick and liquid-saturated coating of photon-absorbing materials in the infrared. This hypothesis could explain its dark appearance both in the infrared and radar data and the persistence of channels seen on the depression floor over the time. Shorelines are observed on the border of Ontario Lacus suggesting past high-stand levels of the alkanofer table. The analogy with the Etosha Pan suggests that Ontario Lacus' depression developed at the expense of a soluble layer covering the region. Dissolution of this layer would be controlled by vertical motions of the alkanofer table over the time. During flooding events, liquid hydrocarbons covering the depression floor would dissolve the surface layer, increasing progressively the diameter of the depression on geological timescales. During drought episodes, liquid hydrocarbons of the underground alkanofer would evaporate, leading to crystallization of "evaporites" in the pores and at the surface of the substratum, and to the formation of the regional soluble layer. The presence of specific landforms (lunette dunes or evaporites) is compatible with such evaporitic regional settings. Alternatively, but not exclusively, the surface soluble layer might have formed by accumulation on the ground of soluble compounds formed in the atmosphere.
\end{abstract}

Keywords: Satellites, surfaces, Titan, surface, Geological processes, Infrared observations, Radar observations

\section{Introduction}

In June 2005 (rev 09), the Narrow Angle Camera (NAC) of the Imaging Science Subsystem (ISS) multispectral instrument

\footnotetext{
${ }^{*}$ Correspondence to: Tel.: +332.51 .12 .55 .84$

Email address: Thomas. Cornet@univ-nantes.fr (T. Cornet)
}

onboard the Cassini spacecraft reported the observation on Titan of a $235 \mathrm{~km}$-long and $75 \mathrm{~km}$-wide dark feature (Fig. 1a), centered at about $72^{\circ} \mathrm{S}$ and $180^{\circ} \mathrm{E}$ (Turtle et al., 2009). By analogy with the numerous lakes and seas of various sizes and shapes that have already been identified at high northern latitudes (Lopes et al., 2007; Stofan et al., 2007; Hayes et al., 
2008), this dark feature has been interpreted as the only large lake in the whole southern hemisphere and has been named Ontario Lacus. Ontario Lacus is uniformly dark in ISS infrared images and has been interpreted as a liquid hydrocarbon coverage, the level and extent of which could change with time (Turtle et al., 2009; Hayes et al., 2011; Turtle et al., 2011a).

In December 2007 (T38 flyby), the Visual and Infrared Mapping Spectrometer (VIMS) acquired its first spatially resolved images of Ontario Lacus (Fig. 1b). From these data, Brown et al. (2008) computed spectral ratios between the inner and outer areas of Ontario Lacus. In the inner area, they identified a spectral absorption feature centered at $2 \mu \mathrm{m}$ and a negative spectral slope at $5 \mu \mathrm{m}$. They interpreted the spectral feature at $2 \mu \mathrm{m}$ as evidence for the presence of liquid ethane covering the floor of Ontario Lacus, as previously hypothesized by Mitri et al. (2007). The $5 \mu \mathrm{m}$ negative spectral slope was interpreted as evidence for the presence of other hydrocarbons (such as methane, propane or butane), which is consistent with recent laboratory measurements (Clark et al., 2009).

Using the same dataset, Barnes et al. (2009) identified three concentric morphological units in Ontario Lacus: a dark inner area interpreted as covered by liquids, a lighter area interpreted as a lakebed or a playa along the southeastern border and a bright annulus surrounding Ontario Lacus interpreted as finegrained organic condensates deposit. Barnes et al. (2009) therefore concluded that this annulus could be an ancient shoreline, suggesting that lake level changes have occurred during Titan's history.

By considering the inner area of Ontario Lacus as a sink for the $5 \mu \mathrm{m}$ radiation, Moriconi et al. (2010) analyzed the composition of the bright annulus in the $5 \mu \mathrm{m}$ atmospheric window, from data acquired during the T38 flyby. After subtracting the spectrum of the inner area from the VIMS cubes, they potentially identified spectral signatures of light hydrocarbons such as propane, acetylene and butane, which are thought to be involved in the composition of Titan's lakes (Cordier et al., 2009). They concluded that Ontario Lacus is a lake covered by liquid methane, ethane and possibly propane, in which some compounds such as butane and acetylene might be dissolved. According to this interpretation, the latter compounds would be able to accumulate along the borders of the lake by evaporation or infiltration of the liquids, just as evaporitic salts do along the shores of terrestrial salty lakes. Recent VIMS T69 observations of dry lake beds south of Ligeia Mare (located in the north polar region) add further credence to the idea of evaporites on Titan (Barnes et al., 2011a). A new observation of Ontario Lacus has been performed by VIMS during the T51 flyby in March 2009, but no analysis of these new data has been published so far.

In December 2008 (T49 flyby), the Cassini RADAR acquired an altimetric profile across the lake, showing that Ontario Lacus is a flat-floored depression that lies in a plain more than $330 \mathrm{~km}$-wide (Fig. 6). The plain is at an elevation of -900 $\mathrm{m}$ relative to the average Titan's radius $(2575 \mathrm{~km})$ and is surrounded by mountains with maximal elevations of $-300 \mathrm{~m}$ (Wye et al., 2009). Wye et al. (2009) interpreted the RADAR altimeter echoes over Ontario Lacus in terms of specular echoes, with a RMS surface height of less than $3 \mathrm{~mm}$ over the $100 \mathrm{~m}$ Fres- nel zone of the RADAR beam footprint. They attributed such a surface smoothness as evidence for the presence of a liquidcovered surface, in agreement with the VIMS interpretations of Brown et al. (2008), Barnes et al. (2009) and Moriconi et al. (2010) and the ISS interpretations of McEwen et al. (2005) and Turtle et al. (2009). Northern lakes similar in size to Ontario Lacus also show a remarkable smoothness, presumably owing to a complete lack of wave activity (Barnes et al., 2011b).

In June and July 2009 (T57-T58 flybys), the first Synthetic Aperture RADAR (SAR) images from the Cassini RADAR experiment were collected over Ontario Lacus (Fig. 1d). Various landforms such as mountains, valleys, rivers, deltas and playas have been identified on these images (Wall et al., 2010). The inner area of Ontario Lacus appears relatively dark in the RADAR images, which has been interpreted to indicate that it is smooth at the RADAR wavelength $(2.17 \mathrm{~cm})$. Subtle variations in radar brightness over the inner area have been interpreted in terms of textural variations of the liquid surface (Wall et al., 2010) or attributed to the fact that the SAR might probe the lake floor through the liquid in some places (Hayes et al., 2010; Wall et al., 2010). Another RADAR dataset has been acquired during the T65 flyby in January 2010 (Fig. 1e). These data have been mentioned previously by Hayes et al. (2010) and Hayes et al. (2011), but never presented as images in a published work.

Hayes et al. (2010) showed that the normalized radar backscatter cross-section $\left(\sigma^{0}\right)$ observed over Ontario Lacus decreases exponentially with the distance to the border. They interpreted this behavior as a radio wave attenuation through a deepening liquid medium, thus in agreement with the altimetry interpretation of Wye et al. (2009). Based on this hypothesis, along with measurements of the dielectric constant of Titan's liquid hydrocarbon analogs and computations of radar penetration depths in those materials (Paillou et al., 2006, 2008a,b), and with help of local topography derived from the T49 altimetry data, they tentatively calculated the near-shore bathymetry of Ontario Lacus where the altimetric profile crosses its border. Then, they extrapolated these results in several locations along Ontario Lacus' border. They concluded that Ontario Lacus is shallower in its western and southwestern parts than in the eastern one. They also demonstrated that the imaginary part of the index of refraction over the radar-dark area is consistent with a composition dominated by liquid hydrocarbons.

Finally, Hayes et al. (2011) interpreted differences in locations of the border derived from ISS (2005, southern summer solstice) and RADAR (2009, southern autumnal equinox) data as evidence for an average shoreline recession of $10 \mathrm{~km}$ on the southwestern border (locally up to $20 \mathrm{~km}$ with more uncertainties). Assuming a loss tangent of $10^{-3}$, this shoreline recession would imply the loss of a $4 \mathrm{~m}$-high liquid layer. Turtle et al. (2011a) also interpreted differences in locations of the border derived from ISS images taken in 2005 (ISS rev09) and 2009 (ISS T51) as evidence for a shoreline retreat of 9 to $11 \mathrm{~km}$ on this southwestern border of Ontario Lacus.

Thus, the current view of Ontario Lacus is that it is a hydrocarbon liquid-covered lake. This lake would experience level-falling episodes in the semi-arid context of Titan's climate (Mitri et al., 2007), responsible for moving shorelines and tem- 
Table 1: Acquisition parameters for ISS, VIMS and RADAR imaging datasets used in this study. The altitude refers to the altitude at closest approach. For RADAR images, since the source of illumination is the antenna itself, the incidence and emission angles are the same, also called look angle, and the phase angle is null (Ford et al., 1980).

\begin{tabular}{|c|c|c|c|c|c|c|c|}
\hline PDS label & incidence $\left({ }^{\circ}\right)$ & emission $\left({ }^{\circ}\right)$ & phase $\left({ }^{\circ}\right)$ & $\begin{array}{l}\text { spatial sampling } \\
(\mathrm{km} / \text { pixel) }\end{array}$ & altitude $(\mathrm{km})$ & $\begin{array}{ll}\begin{array}{l}\text { exposure time } \\
(\mathrm{ms})\end{array} & \\
\end{array}$ & Imaging mode \\
\hline \multicolumn{8}{|c|}{ ISS rev09 (June 2005) } \\
\hline N1496752765_1 & $23-96$ & $0-90$ & $63.9-64.3$ & 2.67 & 448390 & 120000 & NA IRP0 - CB3 \\
\hline N1496753369_1 & $22-96$ & $0-90$ & $63.9-64.3$ & 2.67 & 447360 & 22000 & NA CL1 - MT1 \\
\hline \multicolumn{8}{|c|}{ VIMS T38 (March 2007) } \\
\hline CM_1575507639_1 & $60-73$ & $73-89$ & $41-42$ & $1.7-2.2$ & 6648 & 180 & HiRes $64 \times 32$ \\
\hline CM_1575507241_1 & $62-68$ & $69-79$ & $39-40$ & $1.1-1.6$ & 4225 & 180 & HiRes $64 \times 32$ \\
\hline CM_1575506843_1 & $64-66$ & $45-69$ & $38-42$ & $0.5-1$ & 2012 & 180 & HiRes $64 \times 32$ \\
\hline CM_1575506608_1 & $64-67$ & $21-40$ & $42-57$ & $0.34-0.46$ & 1371 & 80 & HiRes $48 \times 48$ \\
\hline \multicolumn{8}{|c|}{ VIMS T51 (March 2009) } \\
\hline CM_1616816546_1 & $68-84$ & $27-46$ & $73-74$ & $16.2-17.3$ & 32333 & 320 & Normal $32 \times 32$ \\
\hline CM_1616820684_1 & $70-75$ & $13-35$ & $72-74$ & $2.1-5.0$ & 4233 & 240 & Normal $64 \times 64$ \\
\hline CM_1616821854_1 & $72-78$ & $0-3$ & $74-76$ & $0.7-1.7$ & 1389 & 120 & Normal $64 \times 64$ \\
\hline \multicolumn{8}{|c|}{ RADAR SAR T57 (June 2009) } \\
\hline BIBQI46S161_D199_T057S01_V02 & $42-44$ & $42-44$ & - & $0.18-0.3$ & 1387 & - & RADAR SAR \\
\hline \multicolumn{8}{|c|}{ 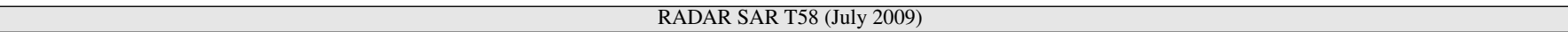 } \\
\hline BIBQI62S167_D200_T058S01_V02 & $26-32$ & $26-32$ & - & $0.3-0.7$ & 1032 & - & RADAR SAR \\
\hline \multicolumn{8}{|c|}{ RADAR SAR T65 (January 2010) } \\
\hline BIBQI78S004_D211_T065S01_V02 & $21-29$ & $21-29$ & - & $0.3-0.5$ & 1109 & - & RADAR SAR \\
\hline BIBQI69S187_D211_T065S02_V02 & $21-29$ & $21-29$ & - & $0.3-0.5$ & 1109 & - & RADAR SAR \\
\hline
\end{tabular}

porary exposition of sediments formed by deposition of particles suspended in the liquid. In the present article we provide an alternative interpretation based on an integrated geomorphological analysis of all available datasets and on a comparison with a terrestrial analog.

After introducing the different datasets and a new method to mitigate the effects of the atmosphere in VIMS images, we first present an interpretative geomorphological map of Ontario Lacus and its surroundings, obtained by merging and crosscomparing all imagery and altimetry data currently available: multispectral data acquired by ISS in July 2005 (rev09), hyperspectral cubes acquired by VIMS in December 2007 (T38 flyby) and in March 2009 (T51 flyby), SAR images acquired by the RADAR in June-July 2009 (T57-58 flybys) and in January 2010 (T65 flyby) and an altimetric profile acquired by the RADAR in December 2008 (T49 flyby). We also compare these data and our geomorphological map with radar, infrared, topographic and geomorphological data acquired on analog landforms located in a semi-arid region of the Earth: the pans of the Etosha Basin (Namibia). Based on this analogy, we discuss the nature of geomorphological, hydrogeological and climatic processes that are responsible for the formation and development of Ontario Lacus.

\section{Data}

\subsection{Imaging Science Subsystem (ISS)}

The ISS instrument is composed of two multispectral cameras (the Narrow and the Wide Angle Cameras, NAC and WAC respectively) that acquire images in the UV, visible and nearinfrared parts of the electromagnetic spectrum, at wavelengths where Titan's atmosphere is usually optically thick (Richardson et al., 2004). The Narrow Angle Camera (NAC) operates from 0.20 to $1.05 \mu \mathrm{m}$ and the Wide Angle Camera (WAC) operates from 0.38 to $1.05 \mu \mathrm{m}$, through narrow bandpass filters and/or infrared polarizers (Porco et al., 2004, 2005). Some filters, which are centered at specific wavelengths corresponding to narrow methane windows and take into account polarization by Titan's haze (West $\&$ Smith, 1991), were especially designed to monitor the surface through Titan's dense atmosphere.

ISS images are single images taken through one or a combination of two filters (one of which may be a polarizing filter to improve the sharpness of surface images by reducing the effects of the haze). Among all the ISS filters, the broadband continuum filter CB3, centered at $0.938 \mu \mathrm{m}$, is the most appropriate to see the surface through the highly scattering and absorbing atmosphere. The atmospheric filter MT1, centered at $0.619 \mu \mathrm{m}$ and imaging only Titan's atmosphere, is another filter often used during image processing (Perry et al., 2005; Porco et al., 2004, 2005).

We used an observation taken by the NAC in June 2005 during rev09 (Turtle et al., 2009). The viewing conditions are summarized in Table 1. This image has been acquired through the combination of "polarizer IRP0" and "broadband continuum CB3" filters to minimize the blurring effects of the haze. The incidence and emission angles vary significantly in the scene (from $22^{\circ}$ to $96^{\circ}$ and from $0^{\circ}$ to $90^{\circ}$ respectively) and the phase angle is $64^{\circ}$. The spatial sampling for this ISS image is $2.67 \mathrm{~km} / \mathrm{pixel}$, but despite the use of a polarizer filter, the actual resolution of the image is probably comprised between 5 and $8 \mathrm{~km}$ due to the blurring effect of scattering by the haze. We also used a second ISS image acquired during the same observation and over the same region, through an atmospheric filter (CL1-MT1).

Both ISS images were calibrated with the CISSCAL procedure described in Porco et al. (2004). This pipeline consists of bitweight correction if needed, bias subtraction, $2-\mathrm{Hz}$ noise removal, dark subtraction, correction for non-linearity, flat-fielding, conversion of the DN to flux and then to $\mathrm{I} / \mathrm{F}$ units, and division by a corrective factor calculated for each filter to fit fluxes expected from theoretical models. We used the "pure at- 
a) ISS rev09 (2005) processed

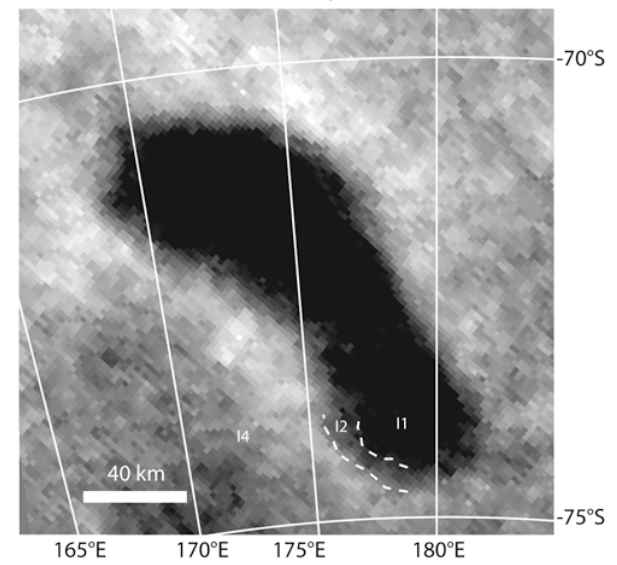

b) VIMS T38 (2007) processed

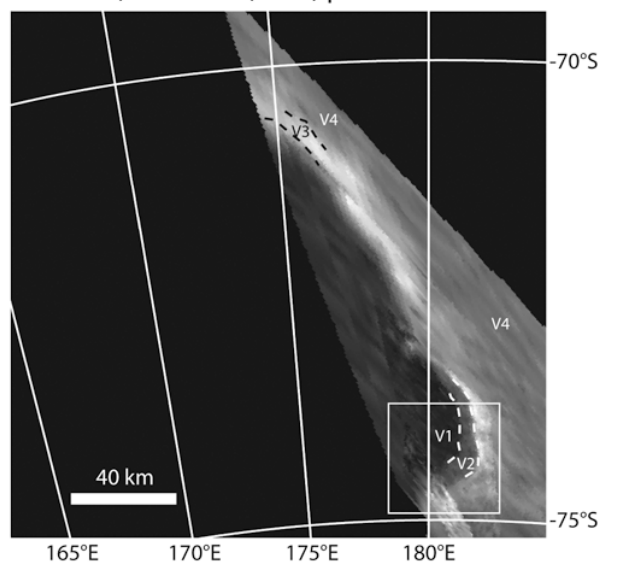

c) VIMS T51 (2009) processed

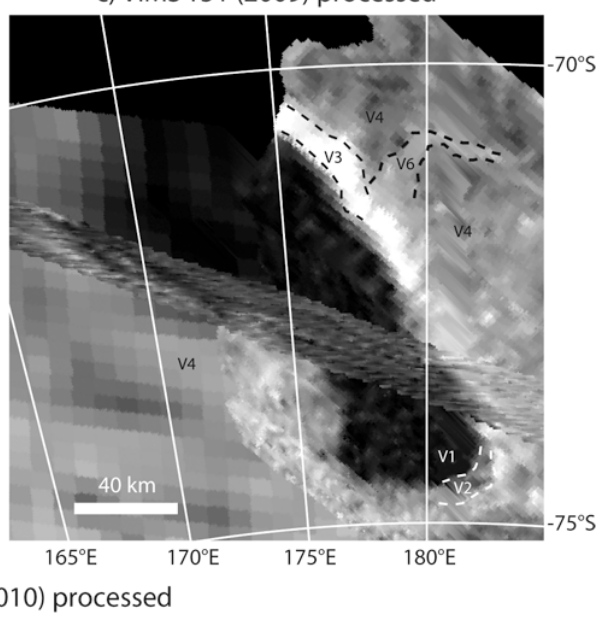

d) RADAR SAR T57-58 (2009) processed

e) RADAR SAR T65 (2010) processed
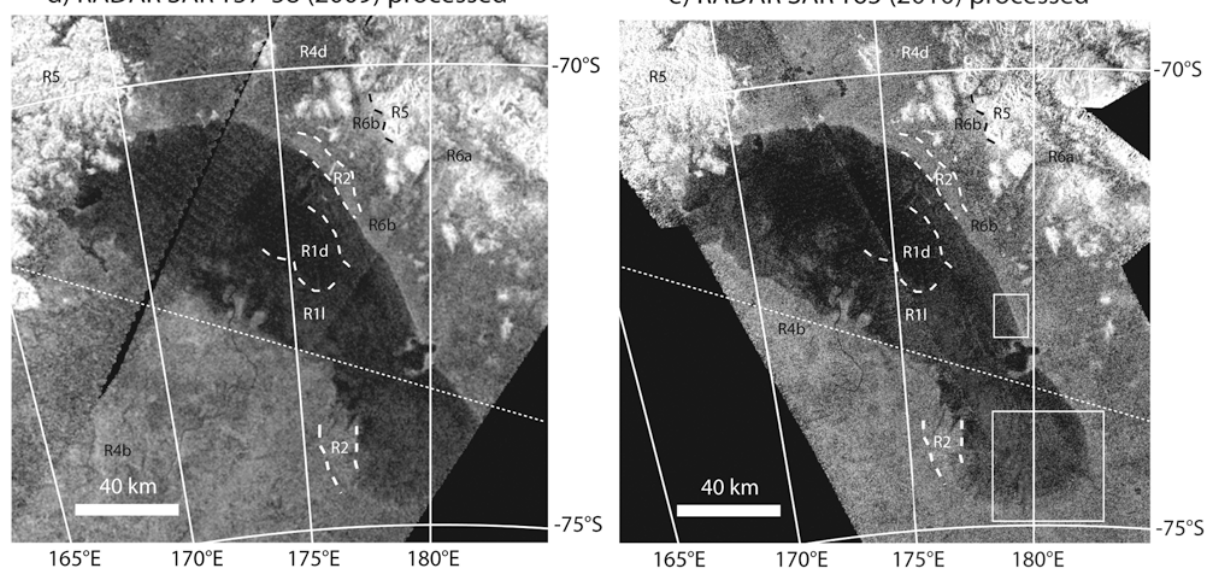

Figure 1: Reprojected views of Ontario Lacus obtained from each dataset. a) ISS $0.938 \mu \mathrm{m}$ image (rev09, 2005).b) VIMS $5 \mu \mathrm{m}$ mosaic (T38, 2007). c) VIMS $5 \mu$ m mosaic (T51, 2009). d) RADAR SAR mosaic (T57-58, 2009). e) RADAR SAR mosaic (T65, 2010). The dotted line on the RADAR mosaics represent the location of the altimetric profile (Fig. 6). The annotated features in each view are described in Section 4.

mospheric" CL1-MT1 image to correct and improve the sharpness of the surface IRP0-CB3 image (Fig. 1a), following the empirical procedure described in Porco et al. (2005) and Perry et al. (2005).

\subsection{Visible and Infrared Mapping Spectrometer (VIMS)}

The VIMS instrument is a hyperspectral camera that records images at 352 separate wavelengths and produces hyperspectral cubes (Brown et al., 2004). It is composed of two distinct detectors, one in the visible from 0.35 to $1.04 \mu \mathrm{m}$ (96 channels) with a spectral sampling of $7.3 \mathrm{~nm}$, and the second in the near-infrared from 0.88 to $5.10 \mu \mathrm{m}$ (256 channels) with a spectral sampling of $16.6 \mathrm{~nm}$. VIMS is able to see Titan's surface in seven narrow atmospheric windows centered at $0.93,1.08$, 1.27, 1.59, 2.03, 2.7-2.8 and $5 \mu \mathrm{m}$ (Sotin et al., 2005).

We used the infrared part of all VIMS cubes acquired over Ontario Lacus during the T38 and T51 flybys (Figs. 1b and c and Table 1). VIMS cubes of Ontario Lacus were acquired at T38 and T51 with a similar spatial sampling, at two different dates separated by a 17 months interval. The T38 observation has already been described by Brown et al. (2008), Barnes et al. (2009) and Moriconi et al. (2010). The T38 data have moderate to high incidence (from $60^{\circ}$ to $73^{\circ}$ ) and emission (from $21^{\circ}$ to $89^{\circ}$ ) angles and moderate phase angles (from $38^{\circ}$ to $57^{\circ}$ ). The spatial sampling ranges from less than 1 up to $2 \mathrm{~km} /$ pixel and the time exposure of $180 \mathrm{~ms}$ is long enough to get a high signal-to-noise ratio. Because of the wide range of emission angles (almost $70^{\circ}$ ), a strong, varying additive atmospheric component due to backscattering by aerosols is present in the cubes (Rodriguez et al., 2006; Le Mouélic et al., 2010).

The T51 dataset has incidence angles similar to those of T38 (from $68^{\circ}$ to $84^{\circ}$ ), but lower emission angles (from $0^{\circ}$ to $46^{\circ}$ ) and higher phase angles (from $72^{\circ}$ to $76^{\circ}$ ). The spatial sampling of the individual cubes ranges from less than 1 to $17 \mathrm{~km} /$ pixel. Most parts of Ontario Lacus are covered by the CM_1616820684_1 cube, with a spatial sampling ranging from 2 to $5 \mathrm{~km} /$ pixel.

We calibrated the VIMS cubes using the pipeline described by Brown et al. (2004) and Barnes et al. (2007) (background subtraction, flat fielding, conversion into specific energy, division by the solar spectrum to convert data into I/F and despiking). We then produced VIMS mosaics by combining several cubes sorted by increasing resolution. 


\subsection{RADAR Mapper}

The Cassini RADAR instrument is an active sensor operating at a frequency of $13.78 \mathrm{Ghz}(\lambda=2.17 \mathrm{~cm}, \mathrm{Ku}$ band $)$ and having four working modes: altimeter, radiometer, scatterometer and Synthetic Aperture Radar (SAR) (Elachi et al., 2004; Janssen et al., 2009). We used images from the SAR mode. SAR images have a spatial sampling better than $1 \mathrm{~km} /$ pixel, depending mainly on the altitude of the spacecraft during the acquisition.

We used the T57 and T58 SAR images of Ontario Lacus, acquired at a two week time interval (Fig. 1d). The SAR T57 image (June 2009) covers the northern part of Ontario Lacus and the SAR T58 image (July 2009) covers its southern part. We also used the SAR T65 images acquired six months later, in January 2010 (Fig. 1e). The incidence/look angles of the T65 observation are relatively similar to those of the T58 observation, both being lower than those of the T57 observation. Spatial sampling of the different observations are nearly the same, all being better than $1 \mathrm{~km} /$ pixel. The viewing conditions are given in Table 1. The images were first navigated using the ISIS 2 software. We then applied a Frost filter to reduce speckle noise (Shi \& Fung, 1994).

We also used the altimetric profile acquired by the RADAR instrument during the T48 flyby in December 2008 (Fig. 6). The elevation accuracy is generally estimated to vary between 35 and $50 \mathrm{~m}$ and the cross-track spatial resolution between 20 and $60 \mathrm{~km}$ (Zebker et al., 2009). For the T49 altimetry data acquired in the Ontario Lacus' region, the along-track spatial sampling (distance between each data point on the profile) is equal to about $2 \mathrm{~km}$, with a footprint diameter of $10 \mathrm{~km}$ (making nearby observations highly correlated with each other). We selected the "first moment corrected surface height" profile from the ASUM table of the PDS data (Stiles, 2008). This profile represents the centroid of echo, corrected for spacecraft range to surface and off-nadir pointing effects (Stiles, 2008; Zebker et al., 2009). To estimate the error on the altimetric profiles, we used the "height span of backscatter distribution" profile, corresponding to the standard deviation of the echo waveform (A. Hayes, personal communication). Theoretical elevation errors based on this profile are comprised between 15 and 20 meters, with a mean value of $16.6 \mathrm{~m}$ across Ontario Lacus.

\subsection{Co-registration of datasets}

We automatically projected the VIMS and ISS images using a mapping code designed at the Laboratoire de Planétologie et Géodynamique de Nantes and described in Rodriguez et al. (2011). We used the ISIS 2 software to project the RADAR images. After projection, offsets remain between the images because accurate estimates of Titan's orbital parameters and exact shape are still lacking. Pointing effects of the spacecraft can also lead to misregistrations. Therefore, we had to adjust the images by hand, so that the contour of Ontario Lacus matches between images. Because of the high spatial resolution of SAR images and of their small co-registration error, the T65 RADAR image was used as a reference to adjust the other images.

On the T57-58 RADAR image, Ontario Lacus appears slightly shifted towards the northeast compared to the T65
RADAR image, by less than $0.2^{\circ}$ in both latitude and longitude. This shift was corrected by a simple translation.

On VIMS T51 data, Ontario Lacus appears slightly shifted towards the northwest compared to the RADAR T65 data (by $0.5^{\circ}$ in longitude and $0.3^{\circ}$ in latitude). This shift was corrected by a simple translation of the mosaic. In doing so, the VIMS mosaic is easily reconciled with the RADAR data, as shown by the strongly similar shape of Ontario Lacus in both datasets (Figs. 1c-e).

On VIMS T38 data, Ontario Lacus appears shifted towards the northeast compared to the RADAR T65 data. A simple translation cannot correct this shift because pointing effects of the camera result in a non-uniform spatial shift of the data (Moriconi et al., 2010). This shift vary from $0.5^{\circ}$ (in the southern part) down to $0.3^{\circ}$ (in the northern part) in latitude, and is equal to $0.5^{\circ}$ in longitude. However, the shape of the southeastern corner of Ontario Lacus in the VIMS T38 mosaic (cube CM_1575506843_1) is almost the same as it is in the VIMS T51 and RADAR T65 mosaics. They have therefore been adjusted so that this contour matches in each dataset, prior to adjust the northern part of Ontario Lacus.

The ISS data have the largest misregistration, with spatial shifts of $3^{\circ}$ in latitude and $6^{\circ}$ in longitude towards the northwest compared to the RADAR T65 data. They have been adjusted to the VIMS data on the basis of spatial features that appear both in the ISS and VIMS data, such as Unit 2 of Barnes et al. (2009).

Finally, the altimetry track was reported on top the RADAR T65 image and morphological features (such as the borders of Ontario Lacus, secondary lakes, rivers and mountains) were used as benchmarks to re-locate the altimetric profile. The best fit between altimetry and SAR data was achieved by shifting the altimetry data $2.6 \mathrm{~km}$ towards the southeast.

\section{Processing of VIMS infrared images}

\subsection{Surface photometry at $5 \mu \mathrm{m}$}

The $5 \mu \mathrm{m}$ images constitute convenient references for surface photometric properties because they are almost free of the atmospheric additive component caused by aerosols backscattering effects (Rodriguez et al., 2006). At this wavelength, surface photometric effects are responsible for the presence of seams in mosaics composed of several cubes acquired under different viewing conditions. To remove these seams, we designed a specific procedure.

We first increased the signal-to-noise ratio by adding images acquired in several spectral channels between 4.88 and $5.05 \mu \mathrm{m}$ (eleven images for T38, eight images for T51 due to a lower signal-to-noise ratio). Then, we corrected the resulting images for photometric effects according to the Lommel-Seeliger single-scattering law (Eq. 1) (Hapke, 1981).

$$
w=\frac{I}{F}(i, e, g) \frac{4\left(\mu_{0}+\mu\right)}{P(g) \mu_{0}}
$$

In this equation, $w$ is the single-scattering albedo of the surface (independent of the viewing geometry), $I / F$ is the signal recorded by VIMS that depends on the incidence $(i)$, emission 

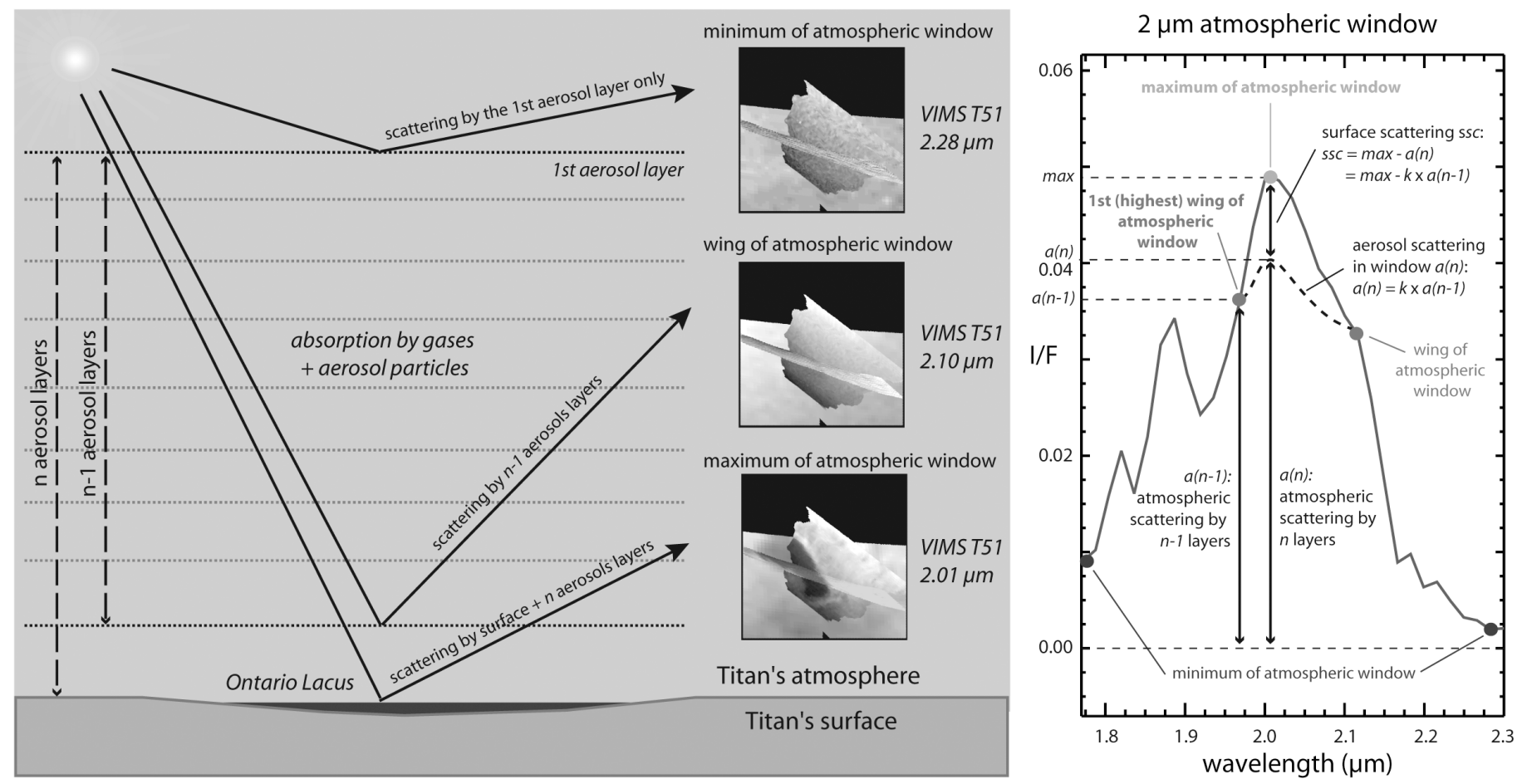

Figure 2: Principle of the empirical haze backscattering correction method for VIMS images applied to the $2 \mu \mathrm{m}$ atmospheric window in the T51 VIMS mosaic, according to the single-scattering approximation. In the edges of the atmospheric window, photons are backscattered by different layers of aerosols. The wavelength called "first wing" is the wavelength integrating the scattering by almost the whole atmosphere (n-1 layers of aerosols) without any contribution from the surface. The image at the center of the window contains both a surface (ssc) and an atmospheric component a(n) integrating the scattering by the $\mathrm{n}$ layers of aerosols present in Titan's atmosphere.

(e) and phase $(g)$ angles, $\mu_{0}$ and $\mu$ are the cosines of the incidence and emission angles, and $P(g)$ is the single-particle phase function of the surface. We tested this surface scattering law with several phase functions. The lunar theoretical particle phase function of Hapke (1963) (Eq. 2) gave the best results for the present regional mapping. The resulting $5 \mu \mathrm{m}$ VIMS mosaics corrected for surface photometry are shown in Figs. 1b (T38) and c (T51).

$$
P(g)=\frac{4 \pi}{5}\left[\frac{\sin g+(\pi-g) \cos g}{\pi}+\frac{(1-\cos g)^{2}}{10}\right]
$$

\subsection{Removal of the additive atmospheric aerosols backscatter- ing component in atmospheric windows}

Analyzing images at various wavelengths is required to recognize compositional variations on Titan's surface. However, imaging the surface of Titan in atmospheric windows at wavelengths shorter than $5 \mu \mathrm{m}$ requires further processing because of the increasing efficiency of haze backscattering with decreasing wavelength (Rodriguez et al., 2006).

Because Ontario Lacus is located at high southern latitudes, the incidence angle is always high, with an emission angle varying from $0^{\circ}$ (nadir observation) to $90^{\circ}$ between T51 and T38. Therefore, the path length through the atmosphere is long and backscattering effects due to the aerosols haze are all the more important. We developed a heuristic method to correct these backscattering effects in the atmospheric windows.
The method is based on the following assumptions : (1) aerosol backscattering is negligible at $5 \mu \mathrm{m}$, thus variations in the $5 \mu \mathrm{m}$ atmospheric window reflect directly variations in the surface photometry; (2) images taken in atmospheric bands, where Titan's surface cannot be seen, are representative of backscattering generated by all layers of aerosols crossed by photons above a given depth in Titan's atmosphere.

The principle of our scattering correction procedure is illustrated in Fig. 2. From the minimum to the maximum of a given atmospheric window, photons are backscattered by deeper and deeper aerosols layers of Titan's atmosphere. Only photons with a wavelength sufficiently close to that of the maximum of this window reach and are backscattered by the surface. Those with a wavelength close to that of the edges of the same window are more likely backscattered by the aerosols only.

The image of the surface at the center of the atmospheric window can therefore be improved as follows. The additive contribution of the atmosphere to the signal recorded at the maximum of the atmospheric window is estimated by multiplying the signal received at the first wing (Fig. 2) by a $k$ factor. This $k$ factor represents the ratio between the contribution of the whole thickness of the atmosphere ( $n$ aerosol layers in Fig. 2) and the contribution of the atmosphere in the "first wing" $(n-1$ aerosol layers in Fig. 2). This contribution is then subtracted from the image acquired at the maximum of the atmospheric window.

The value of the $k$ factor is computed automatically by an algorithm designed to minimize the standard deviation created by seams in a mosaic composed of several cubes acquired with 
a)

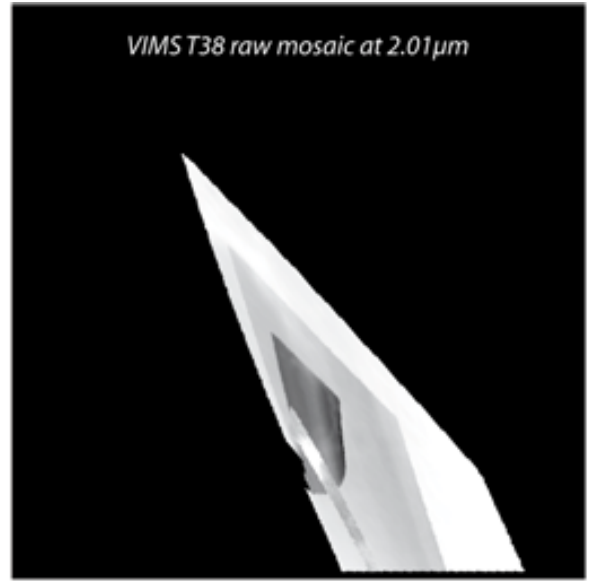

b)

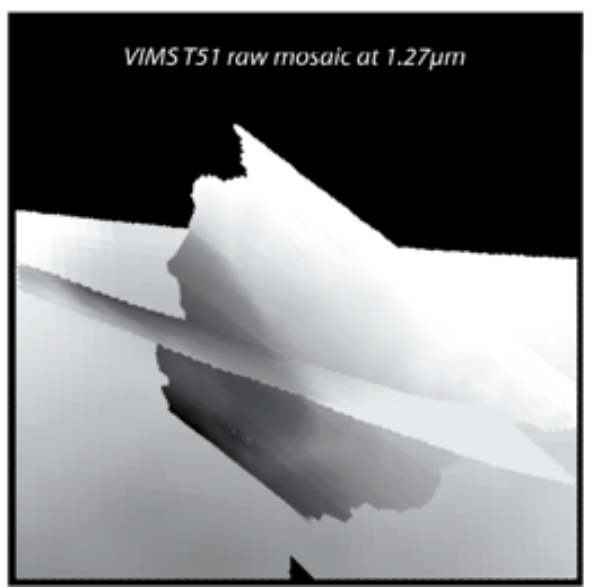

VIMS T38 mosaic corrected for atmospheric scattering and surface photometry at $2.01 \mu \mathrm{m}$
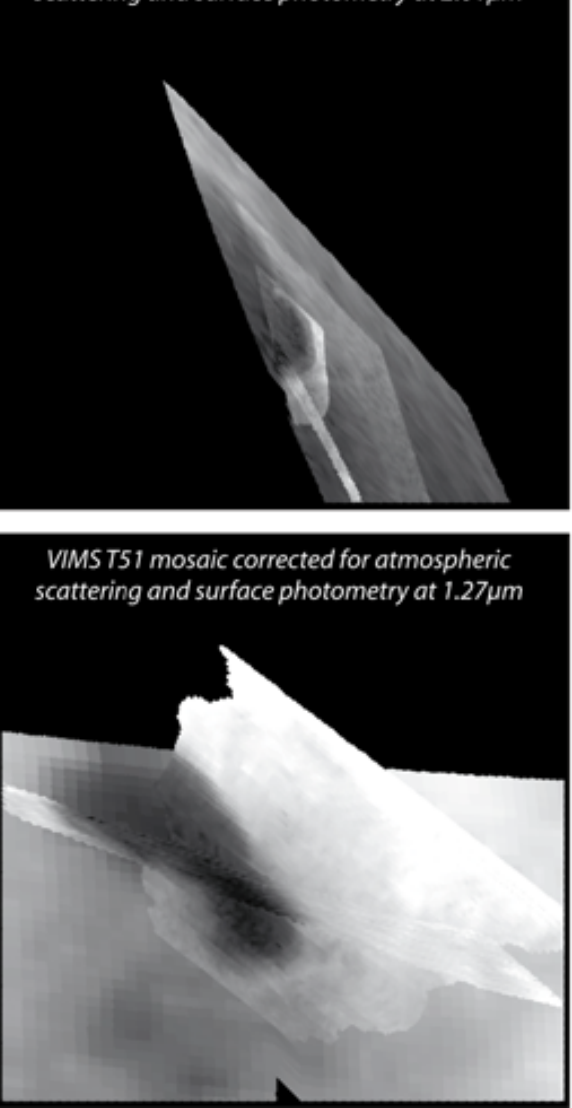

VIMS T38 RGB color composite with corrected images:Red: $5 \mu \mathrm{m}$; Green: $2.78 \mu \mathrm{m}$; Blue : $2.01 \mu \mathrm{m}$

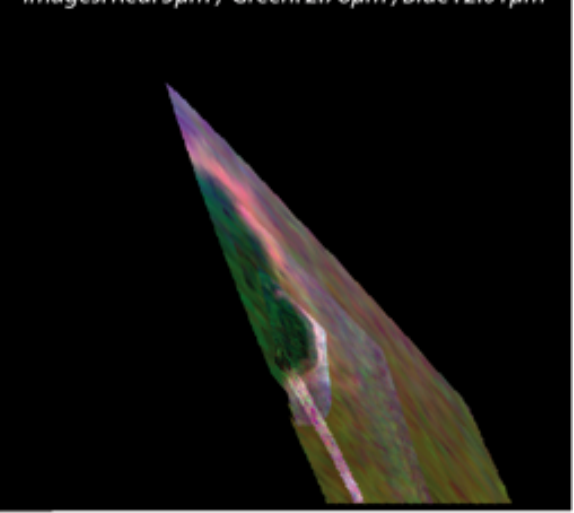

VIMS T51 RGB color composite with corrected images: Red: $5 \mu \mathrm{m}$; Green: $2.01 \mu \mathrm{m}$; Blue : $1.59 \mu \mathrm{m}$

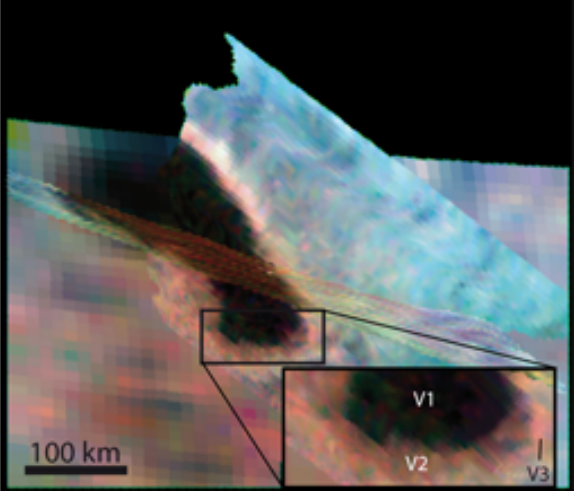

Figure 3: VIMS images corrected for haze backscattering and surface photometry. Selected surface images show a strong atmospheric component, often encountered at $1.27 \mu \mathrm{m}$ but more rarely at $2.01 \mu \mathrm{m}$. a) From left to right : VIMS T38 raw mosaic at $2.01 \mu \mathrm{m}$, VIMS T38 corrected mosaic at $2.01 \mu \mathrm{m}$ and a RGB color composite with R: $5 \mu \mathrm{m}, \mathrm{G}: 2.78 \mu \mathrm{m}$ and B: $2.01 \mu \mathrm{m}$. b) From left to right : VIMS T51 raw mosaic at $1.27 \mu \mathrm{m}$, VIMS T51 corrected mosaic at $1.27 \mu \mathrm{m}$ and a RGB color composite with R: $5 \mu \mathrm{m}, \mathrm{G}: 2.01 \mu \mathrm{m}$ and B: $1.59 \mu \mathrm{m}$. Scale bar displayed on the VIMS T51 RGB mosaic is common for all mosaics.

various viewing geometries. Indeed, two overlapping cubes, acquired at the same date but under different viewing conditions integrate a different additive atmospheric scattering component. This results in the presence of a seam between the two cubes. Our algorithm computes the $k$ factor to ensure that the overlapping cubes have the same $w$ value on each side of the seam so that it disappears. Images corrected for atmospheric backscattering and surface photometry are displayed in Figs. 3a and b.

We also used the Minimum Noise Fraction (MNF) transform to decorrelate (forward MNF) and then suppress (inverse MNF) instrumental noise from data. This technique allows a more accurate view of surface features at $5 \mu \mathrm{m}$ (Le Corre et al., 2009; Le Mouélic et al., 2008). For example, this procedure emphasizes channels on the floor of Ontario Lacus in the T38 observation (Fig. 4a).

\section{Description of processed images}

\subsection{ISS}

Three main features can be identified on the ISS IRP0-CB3 image (Fig. 1a). The first one (I1) is very dark and uniform at
$0.938 \mu \mathrm{m}$. The second feature (I2) is located along Ontario Lacus' edges and is particularly well seen along the southwestern edge of I1. This feature is brighter than I1 but darker than the next one, I4. The third feature (I4) covers the surroundings of Ontario Lacus.

\subsection{VIMS}

Five distinct features are visible on the VIMS images (Figs. $1 \mathrm{~b}$ and $\mathrm{c}$ ). The first one (V1) is dark at all wavelengths corresponding to atmospheric windows. It was interpreted as an area covered by liquid hydrocarbons by Brown et al. (2008).

After application of the MNF process to the T38 VIMS cubes (Section 3.2), channels appear in the southernmost part of V1 (Fig. 4a). They appear slightly darker than the rest of V1. The significance of this observation will be discussed in Section 5.

The second feature (V2) is particularly well discernible along the southeastern border of V1. It is not as dark as V1 but it is darker than the surroundings and was interpreted as an exposed lakebed by Barnes et al. (2009). V2 appears in brown on the false color composite derived from the T51 VIMS observation (Fig. 3b). It surrounds continuously the southern part of Ontario Lacus. 


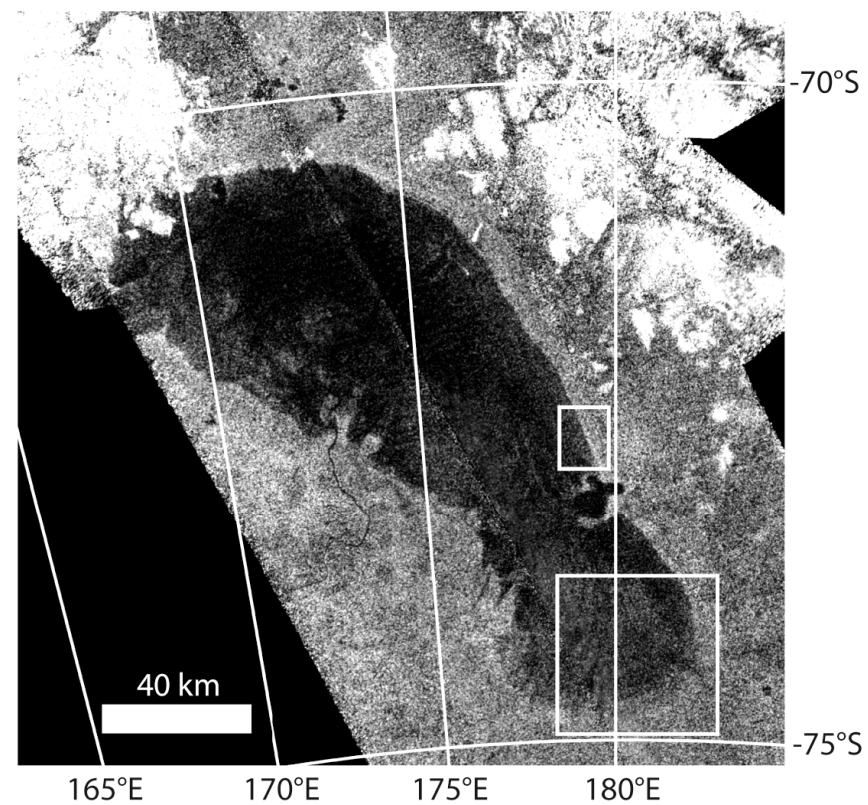

a) Southern border

VIMST38

MNF reduction

at $5 \mu \mathrm{m}$
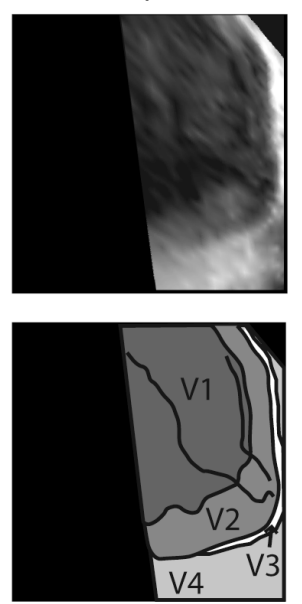

RADART65
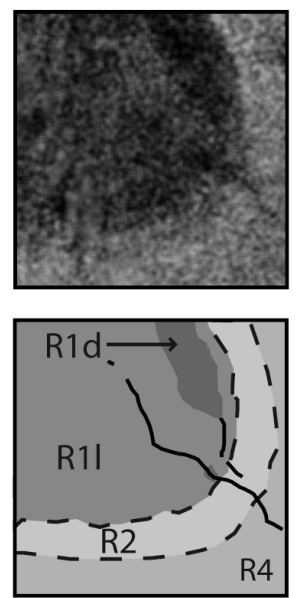

b) Eastern border

RADAR T57-58
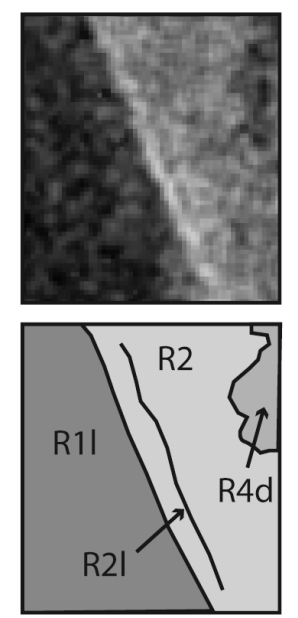

Figure 4: Zoom on infrared and radar features on Ontario Lacus. a) Southern border of Ontario Lacus, displaying channels on the floor in both infrared and radar data. b) Eastern border of Ontario Lacus emphasizing the R21 feature.

The third feature (V3) is particularly bright in the $5 \mu \mathrm{m}$ atmospheric window. It forms a discontinuous strip located along the northeastern and southeastern borders of V1 and V2. The T51 observation shows that either this unit does not exist along the western border of Ontario Lacus, or it is significantly reduced in either width or contrast. V3 has been interpreted as an ancient shoreline by Barnes et al. (2009).

The fourth feature (V4) covers the grey surroundings of Ontario Lacus. It does not exhibit a striking infrared spectral behavior.

The fifth feature (V6) can be seen in the T51 dataset, northeast of Ontario Lacus. It is a bright linear feature visible on Figs. 1c and 3b. It stretches across V4 and seems to be linked to V3.

\subsection{RADAR}

SAR images acquired during T57, T58 and T65 allow a thorough description of Ontario Lacus and its near environment. Five major features can be differentiated. Some of them can be subdivided further.

The first major feature (R1) covers Ontario Lacus and is subdivided in two regions. The first region (R1d) appears uniformly dark and is therefore very smooth at the Cassini RADAR wavelength $(2.17 \mathrm{~cm})$. It is located mainly in the northern inner part of Ontario Lacus (Figs. 1d and e). The second region (R11) appears less dark than R1d, with a salt-and-pepper texture. This texture is attributable to speckle noise. The fact that this lighter unit with a salt-and-pepper texture appears at exactly the same locations on T57-58 and T65 RADAR images, taken at a 6 months interval, and with different viewing geometries, suggests that it is a specific geomorphological unit different from R1d.
Linear features resembling channels can be seen inside R11 (Fig. 4a). The darkness of R1d and R11 have previously been interpreted as evidence for an entire liquid coverage of Ontario Lacus (Hayes et al., 2010; Wall et al., 2010). According to this interpretation, R11 would represent either textural variations of the liquid surface (Wall et al., 2010), or the probing of Ontario Lacus' floor through the liquids (Hayes et al., 2010). R1d would therefore represent either a very smooth liquid surface (Wall et al., 2010), or areas where the liquid layer that covers Ontario Lacus' floor is so thick that it is not fully penetrated down to the floor by the radar waves (Hayes et al., 2010).

The second major feature (R2) is a bright strip that surrounds the eastern and southern borders of Ontario Lacus. Its brightness may imply that this area is rougher and/or possesses a subsurface structure and/or a dielectric constant differing from that of the surroundings of Ontario Lacus. Linear features (R2l) can be seen in the eastern part of R2 and follow Ontario Lacus' border (Fig. 4b). The eastern part of R2 has previously been interpreted by Wall et al. (2010) as a wave-generated beach that contains past shorelines (R2l).

The third major feature (R4) covers the moderate $\sigma^{0}$ surroundings of Ontario Lacus, appearing in grey on Figs. 1d and $\mathrm{e}$, and is subdivided in two regions. The first region (R4b) represents the brightest parts of this area while the second region (R4d) represents the darkest ones. Linear and small circular features resembling channels and lakes can be seen in these regions.

The fourth major feature (R5) is located north of Ontario Lacus. It appears as radar very bright terrains (high $\sigma^{0}$ values). This unit presents therefore strong topographic heterogeneities and/or is very rough. R5 also contains triangular facets. These radar patterns are typically caused by the topography of mountains (Ford et al., 1980). Wall et al. (2010) therefore interpreted 


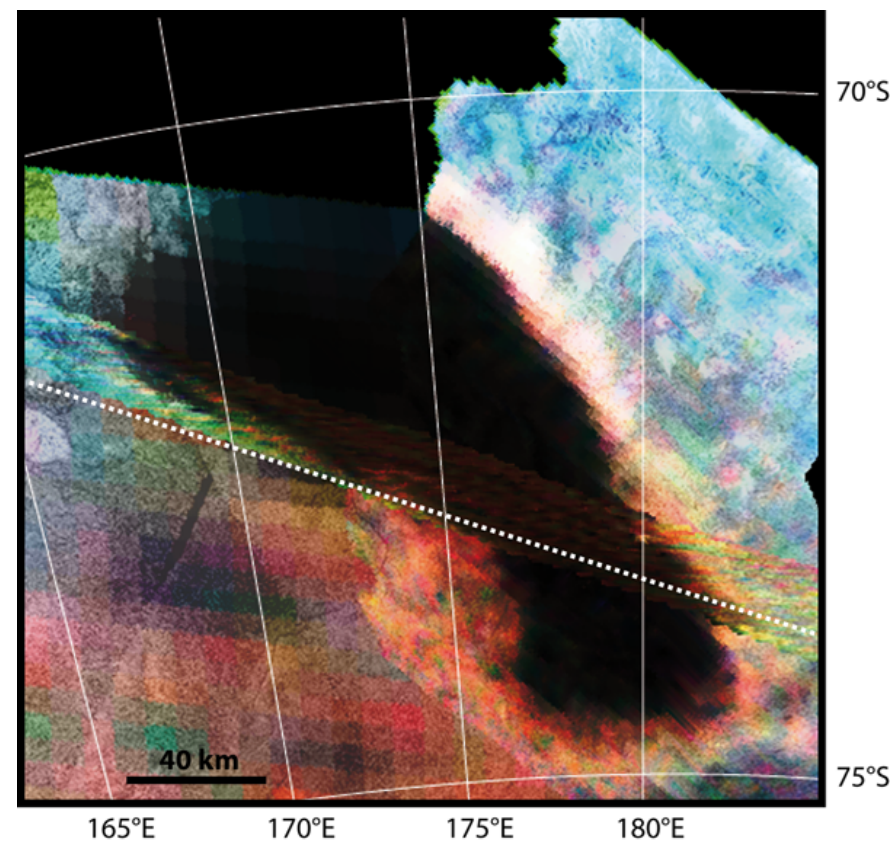

Figure 5: Overlay of VIMS T51 false color composite of Fig. 3b (R: $5 \mu \mathrm{m}$; G: $2.01 \mu \mathrm{m}$; B: $1.59 \mu \mathrm{m}$ ) with T57-58-65 RADAR images (coded as variation in intensity). R11 and R1d correlate with V1. R2 correlate with V2 (appearing here in dark red/brown). V3 is very bright and is located east of Ontario Lacus. The white dashed line represents the location of the altimetric profile displayed on Fig. 6.

\section{R5 as mountains.}

The fifth major feature (R6) seems to be associated with R5. It can be subdivided in two regions. The first region (R6a) is a large linear pattern resembling and interpreted as a valley by Wall et al. (2010). It is located in R5 and is centered at $71^{\circ} \mathrm{S}$ and $180^{\circ} \mathrm{E}$. The second region (R6b) is radar-bright and is located around R5 and in the valley-like features. A part of this region is located at the western end of R6a and has been interpreted by Wall et al. (2010) as an alluvial fan.

\section{Integrated geomorphological interpretation}

The information provided by all infrared and radar observations is summarized in Table 2. Figure 5 is a composite illustrating the spatial correlation between the T51 VIMS mosaic and the T57-58-65 RADAR SAR mosaic. VIMS and ISS are sensitive to compositional variations and grain size effects of the top few microns below the surface, whereas the SAR is mainly sensitive to topography, roughness and dielectric constant of the surface and sub-surface. The datasets are therefore complementary. From all these data, we compiled a synthetic geomorphological map of Ontario Lacus (Fig. 7).

To better constrain the geomorphological significance of features defined in Section 4, we also used the T49 altimetric profile. In Fig. 6, we compare VIMS, RADAR and topographic signals along the track of the T49 altimetric profile.

The altimetric profile shows that Ontario Lacus is essentially a $100 \mathrm{~km}$-wide flat-floored depression lying in the lowest part of a topographic basin. Elevation differences across this basin do not exceed $200 \mathrm{~m}$ over more than $330 \mathrm{~km}$. It is surrounded by small mountains with elevations of a few hundred meters above the basin. We now describe each geomorphological unit of the map compiled from all these data (Fig. 7).

\subsection{Units $A$ and B: Depression floor}

The depression floor appears as the dark features I1 and V1 in infrared data, and R1d and R11 in RADAR data. While nothing shows up inside I1 in the ISS image, striking linear features resembling channels appear in the southern corner of the VIMS T38 processed mosaic (Fig. 4a). Because VIMS is able to see only the top few tens of microns below the surface, the visibility of the channels in VIMS images implies that this part of the depression was not liquid-covered at the time of this observation, except for the channels themselves. This part of Ontario Lacus was most probably soggy, since Clark et al. (2010) found that the spectral properties of soggy surfaces are consistent with the low $w$ values recorded by VIMS on Ontario Lacus. Unfortunately, the spatial resolution of T51 VIMS data is not sufficient to see whether or not these channels are still present 17 months after the T38 observation. However, these channels can be seen in the R11 region in the RADAR data, at the same location, 2 years later. They appear darker than their surrounding (R11), are therefore smoother and most probably filled by liquids.

It should be noted that in some terrestrial examples, surface currents can produce such "channels" within liquid layers, in very specific contexts (such as particles transported by surface currents in estuaries). However, due to their identical location at a 2-years interval both in VIMS and RADAR data, we do not favor this hypothesis. Our interpretation that they are liquidfilled channels running on the exposed floor of Ontario Lacus is consistent with the fact that they appear uniformly dark on RADAR images, whereas their surrounding (R11) is lighter and displays a diagnostic salt-and-pepper texture.

The depression floor can be subdivided in two regions in RADAR data. R1d, mostly located in the northern central part of Ontario Lacus, displays a radar very uniform and low signal, which is consistent with a quiescent liquid coverage. R11, located around R1d, appears lighter than R1d and in the same locations both in T57-58 and T65 mosaics, taken at a 6 months interval. R11, displaying a salt-and-pepper texture in the same areas at two different dates, and containing channels that can be detected in both infrared and radar data, is therefore interpreted as the exposed floor of Ontario's depression. The low $w$ and $\sigma^{0}$ values recorded over R11 suggests that this depression floor is composed of a smooth liquid-hydrocarbon saturated substratum. A liquid-hydrocarbon layer would thus cover about 53 $\%$ of the liquid-saturated substratum, of which almost $70 \%$ is located in the northern part of Ontario Lacus.

The alternation of R11 (exposed floor) and R1d (liquidcovered floor) along the track of the altimetric profile is consistent with the existence on the depression floor of smallamplitude undulations in altimetry data (Fig. 6). These undulations are smaller in amplitude than the theoretical error on absolute elevation given by the "height span of backscatter distribution" profile. However, they are spatially correlated to R11-dominated regions whereas they are almost absent in R1d. 
Table 2: Characteristics of the different features identified in ISS, VIMS and RADAR datasets and corresponding interpretations on the geomorphological map (Fig. 7).

\begin{tabular}{|c|c|c|c|}
\hline Geomorphological units & ISS & VIMS & RADAR \\
\hline A: Liquid-covered floor & \multirow[b]{2}{*}{ I1: dark area } & \multirow{2}{*}{$\begin{array}{l}\text { V1: dark area at all wavelengths, containing } \\
\text { channels }\end{array}$} & R1d: uniformly dark area \\
\hline B: Exposed (wet) floor & & & $\begin{array}{l}\text { R11: lighter parts of Ontario Lacus with salt-and- } \\
\text { pepper texture with channels }\end{array}$ \\
\hline C: Past flooded area & \multirow{2}{*}{ I2: quite dark area } & \multirow{2}{*}{$\begin{array}{l}\text { V2: quite dark area at } 5 \mu \mathrm{m} \text {; brown on the T51 } \\
\text { RGB false color composite }\end{array}$} & $\begin{array}{l}\text { R2: Rough terrains surrounding Ontario Lacus' } \\
\text { eastern and southern borders }\end{array}$ \\
\hline D: Past shorelines & & & $\begin{array}{l}\text { R21: lines along the eastern border of Ontario La- } \\
\text { cus, in unit R2 }\end{array}$ \\
\hline $\begin{array}{l}\text { E: Lunette dunes (?) } \\
\text { Evaporitic deposits (?) }\end{array}$ & \multirow{5}{*}{ I4: infrared neutral area } & V3: bright strip at $5 \mu \mathrm{m}$, east of Ontario Lacus & $\begin{array}{l}\text { R4 (R41: lighter / R4d: darker): moderate } \sigma^{0} \\
\text { surroundings of Ontario Lacus. Area containing } \\
\text { channels and small isolated lakes }\end{array}$ \\
\hline F: Alluvial plain & & \multirow[b]{2}{*}{ V4: infrared neutral area } & \\
\hline G: Mountains & & & $\begin{array}{l}\text { R5: very bright terrains with triangular facets, } \\
\text { northwest and northeast of Ontario Lacus }\end{array}$ \\
\hline $\mathrm{H}$ : Intramountain valley & & $\begin{array}{l}\text { V6: linear bright feature at } 5 \mu \mathrm{m} \text { and in the T51 } \\
\text { RGB color composite }\end{array}$ & R6a: linear feature in mountains (unit R5) \\
\hline I: Mountains pediments & & V4: infrared neutral area & $\begin{array}{l}\text { R6b: light grey terrains around mountains and on } \\
\text { valley floors }\end{array}$ \\
\hline
\end{tabular}

If this correlation is significant, it is consistent with the interpretation that the depression floor is exposed on topographic highs (R11), whereas it is covered by liquids in topographic lows (R1d). This suggests the existence of an alkanofer close to the topographic surface, thus saturating in liquids the subsurface. The alkanofer level would stand above the topographic surface in topographic lows, whereas it would remain underground below topographic highs (Fig. 7).

\subsection{Units $C$ and D: Past flooded area and associated shore- lines}

$\mathrm{V} 2$, also corresponding to R2 and I2, is mainly visible in the southern part of Ontario Lacus. This feature does not display a sharp boundary with R11, as would be expected for a sharp transition between a smooth (liquid) and a rough (solid) surface. Altimetry data show that V2 is located a few meters (about $3-4 \mathrm{~m}$ ) higher than the rest of Ontario Lacus. This difference in elevation is smaller than the theoretical error on absolute elevation, comprised between 18 and $22 \mathrm{~m}$ in this part of the profile (Fig. 6). However, this change in elevation correlates with the limit between $\mathrm{V} 1$ and V2, I1 and I2 and R11 and R2. We therefore hypothesize that a bank-shaped transition between the depression and the surroundings is present at this location.

Linear features (unit R2l) are observed in R2, along the eastern border of Ontario Lacus. These features resemble past shorelines, as previously mentioned by Wall et al. (2010). Therefore, V2 (also corresponding to R2 and I2) is interpreted as a past flooded area bearing witness of past high stand level of the liquids. This confirms the expected vertical motion of the alkanofer table over the time in a lake environment.

\subsection{Unit E: Lunette dunes? Evaporitic deposits?}

The types of margin as seen around the depression's borders differ strongly in their shape in map view. The eastern border is convex and significantly smoother than the concave western one. V3 is located along the smooth and convex border. Altimetry data (Fig. 6) show that this unit is associated with slight topographic bumps that are 2 to $4 \mathrm{~km}$-wide and 7 to $14 \mathrm{~m}$-high. Once again, these values are contained within the theoretical absolute error bars on the altimetric profile. However, since they correlate with distinct objects seen in images, they may have a significance. We therefore tentatively interpret these features as meter-scale bumps of unknown amplitude.

In numerous instances on Earth, similar topographic bumps along convex borders of asymmetric depressions lying in flat regions correspond to dunes formed by accumulation of sediments provided by wind deflation over depression floors. These are called lunette dunes. It has been demonstrated that asymmetries in the shape of these depressions are due to the effect of wind blowing from their concave and rough border towards their convex and smooth border (Goudie \& Wells, 1995). The interpretation of $\mathrm{V} 3$ as lunette dunes could pertain to the case of Ontario Lacus, since Global Circulation Models (GCMs) predict that regional winds in this region blow from the SSW to the NNE (Tokano, 2008).

Lorenz et al. (1995) computed the minimum wind friction speed to carry Titan's surface particles in saltation and found it is equal to $0.03-0.04 \mathrm{~m} . \mathrm{s}^{-1}$ for particles with a diameter of $200-300 \mu \mathrm{m}$. Using a logarithmic wind profile (Tokano, 2008 ), it corresponds to a wind speed of $0.73-0.98 \mathrm{~m} \cdot \mathrm{s}^{-1}$ at $90 \mathrm{~m}$ from the surface. Lorenz et al. (2010b) showed that the near-surface wind speed over Ontario Lacus, calculated at this altitude of $90 \mathrm{~m}$ using the TitanWRF model, can exceed the $0.73 \mathrm{~m} . \mathrm{s}^{-1}$ lower threshold value during several terrestrial years $\left(200^{\circ}<L_{S}<300^{\circ}\right)$. This wind speed could even exceed the $0.98 \mathrm{~m} . \mathrm{s}^{-1}$ upper threshold value, with wind speed peaks equal to $1.5-2.0 \mathrm{~m} . \mathrm{s}^{-1}$ in early southern summer $\left(200^{\circ}<L_{S}<240^{\circ}\right)$. Therefore, such wind speeds would be able to carry episodically in saltation particles with a diameter equal or even coarser than $300 \mu \mathrm{m}$. Whatever the size of the potentially transported particles, their deposition would occur just behind the downwind border of the depression, where wind speed decreases due to the abrupt change in roughness that occurs there between the depression floor and its surroundings.

An alternative explanation is that this $5 \mu \mathrm{m}$ bright strip is 
a)

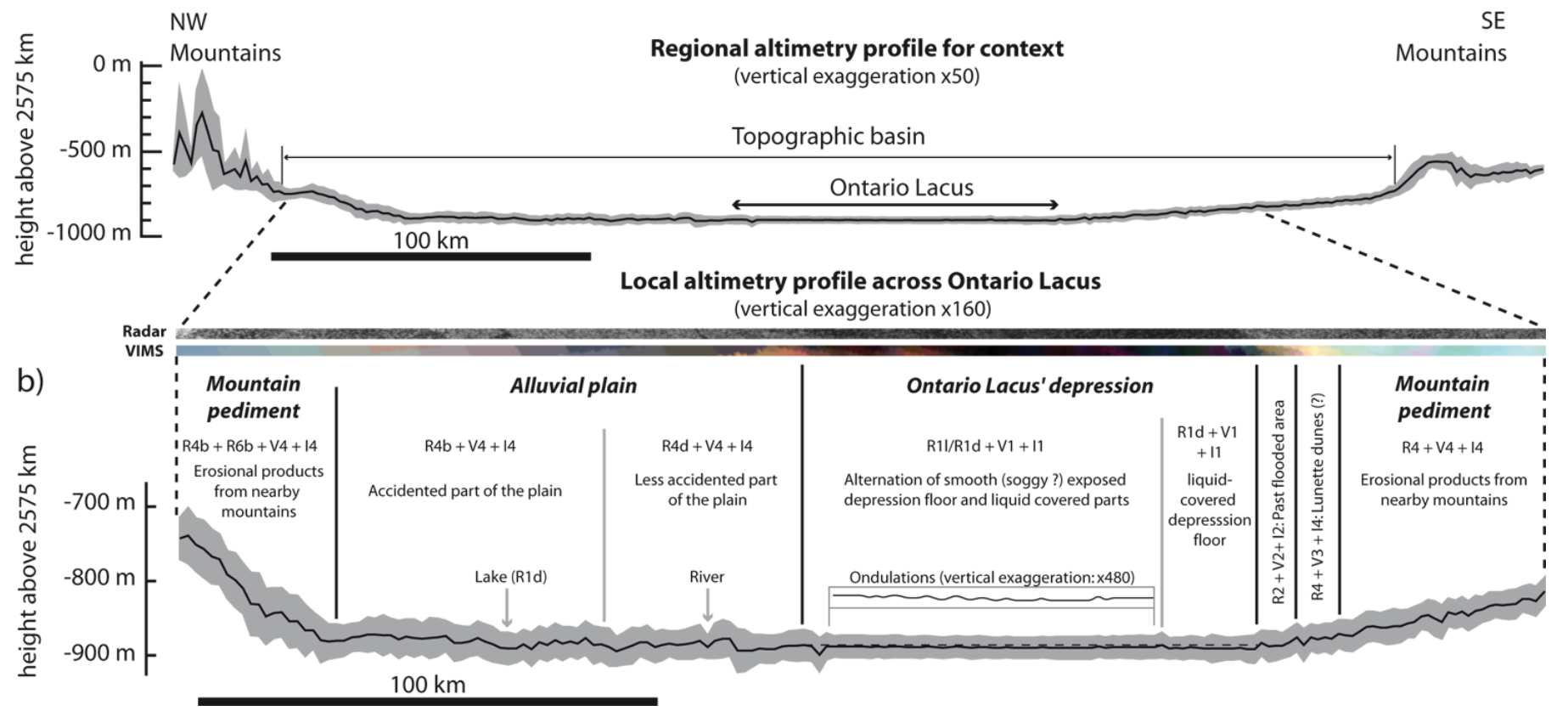

Figure 6: T49 altimetric profile acquired in December 2008 across Ontario Lacus. a) Regional altimetric profile for context. b) Local altimetric profile centered on Ontario Lacus' area covered in the images of Fig. 1, with geomorphological units and interpretations. An estimate of the error in altitude is given in grey (see Section 2.3). The location of the profile is indicated on Fig. 5. Because the area is extremely flat, the altimetric profile is reported with a vertical exaggeration of $\times 50$ for the context profile and of $\times 160$ for the local profile. VIMS T51 and RADAR T57-58-65 tracks corresponding to the T49 altimetry track are shown for comparison. Dashed line on the local profile joins the borders of Ontario Lacus and underlines the depression.

formed by evaporitic deposits, in accordance with Barnes et al. (2009) interpretation of V3 as a "bathtub ring" witnessing past high-stand liquid levels. Such kind of deposits has also been potentially identified by Barnes et al. (2011a) with VIMS data in and around some of Titan's northern lakes.

\subsection{Unit F: Alluvial plain}

According to altimetry data (Fig. 6), Ontario Lacus is located in a topographic basin composed of I4, V4, R4b and R4d. The difference in elevation in this region does not exceed $200 \mathrm{~m}$ over more than $330 \mathrm{~km}$ from the lowest parts of the depression floor to the highest parts of the basin. Some parts of the basin appear brighter (R4b) than others (R4d) in the RADAR images. Because of the flat topography, this difference is most probably due to the roughness or the composition of the terrains. Channels and small rounded lake-like features in RADAR images (Figs. 1d and e) suggest that this area is an alluvial plain.

\subsection{Units $G$ and H: Basement outcrops in mountains and as- sociated valleys}

The alluvial plain is surrounded by mountains about $500 \mathrm{~m}$ high according to altimetry data (Fig. 6). These mountains are also visible in the RADAR data (R5) thanks to their high $\sigma^{0}$ values compared to those of the plain (Figs. 1d and e). Dendritic valleys appear in the RADAR data within these mountains and clearly underline the existence of relief. Surprisingly, the mountains do not appear distinctly from the plain in the ISS and VIMS data. The valley seen in VIMS data is underlined as unit $\mathrm{H}$ in Fig. 7.

\subsection{Unit I: Mountain pediment and valley sedimentary fills}

Radar-bright materials are present around mountains (R6b) and on the floor of valleys (R6a) incised in mountains. These radar-bright materials can be interpreted as sedimentary accumulations composed of erosional products from mountains. The sedimentary fill of the valley located at $70.5^{\circ} \mathrm{S}$ and $180^{\circ} \mathrm{E}$ in the RADAR image is also visible as V6 in the VIMS T51 false color composite. It is connected to V3. This $5 \mu \mathrm{m}$-bright area would therefore correspond to a sedimentation area partially fed by erosional products transported from the nearby mountains to the depression border.

\subsection{Synthesis}

We interpret Ontario Lacus as a nearly flat-floored depression. Areas that are uniformly dark on SAR images (R1d, mostly located in the northern part of the depression) would correspond to the lowest regions of this depression, where the level of an "alkanofer" would rise above the topographic surface, thus covering the depression floor with a thin liquid layer. Areas that are brighter in the RADAR images and have a saltand-pepper texture (R11, mostly located in the southern part of the depression) would correspond to slightly higher regions where the relative level of the "alkanofer" is too low to rise above the topographic surface but saturates the substratum in liquids. Wet sediments would thus be exposed in these regions. Channels can be seen in infrared and radar data in these parts of Ontario Lacus. Interestingly, the liquid-covered portions and the exposed portions of the depression floor cannot be differentiated on ISS and VIMS images. This can be explained by the 


\section{GEOMORPHOLOGICAL MAP}

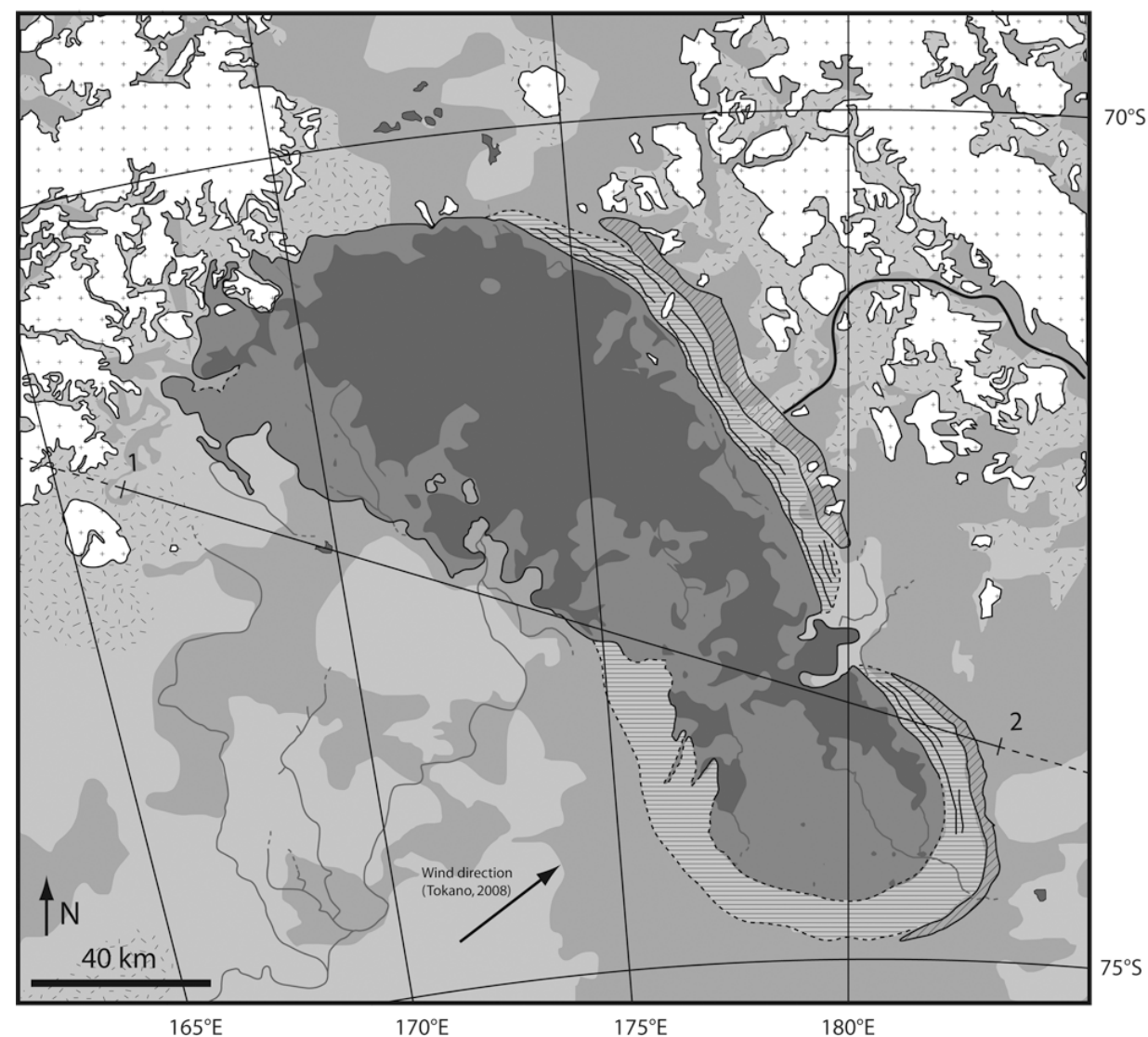

INTERPRETATIVE CROSS-SECTION
A: Liquid-covered depression floor (R1d, part of V1, part of I1)

B: Exposed (perhaps wet) depression floor (R11, part of V1, part of I1)

C: Past flooded area $(R 2, V 2,12)$

D: Past shorelines (R21, part of V2, part of 12)

E: Lunette dunes (?) (part of R4, V3, part of 14) Evaporites (?)

F: Alluvial plain (R4, part of V4, part of 14$)$ Smooth/flat area (R4d, part of $V 4$, part of 14 ) Rough/accidented area (R4b, part of $V 4$, part of 14 )

G: Basement outcrops in mountains ( $R 5$, part of $\mathrm{V}$, part of 14 )

$\mathrm{H}$ : Axis of the valley seen in VIMS data (R6a, V6, part of 14)

I: Mountain pediment (R6b, part of 44 , part of 14 )

\section{Clear contour}

Unclear contour

Channel

vertical exaggeration $\times 10$

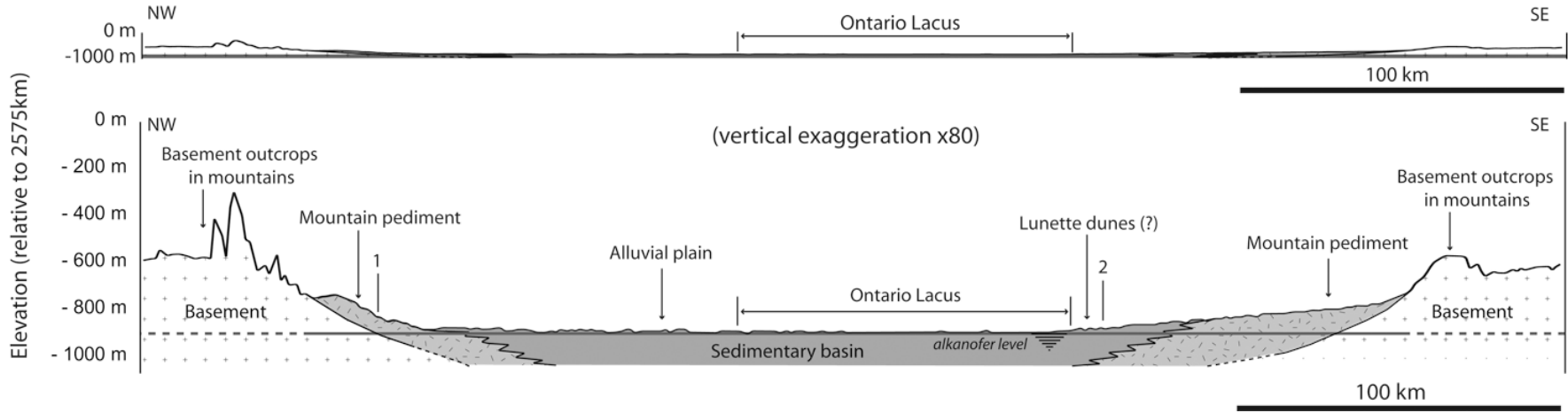

Figure 7: Interpretative geomorphological map and cross-section of Ontario Lacus on Titan. Ontario Lacus is interpreted as a partially liquid-covered flat-floored depression, lying in an extremely flat sedimentary basin surrounded by small mountains ridges few hundred meters high. In such a topographically flat context (see the upper cross section, represented with a vertical exaggeration of only $\times 10$ ), the alkanofer level might be close to the surface in order to inundate only portions of Ontario Lacus where it lies above the topographic surface. In other locations, the alkanofer might lie slightly below the topographic surface, as indicated by the presence of small lakes and channels around Ontario Lacus.

fact that a saturated medium can produce very low $w$ values, similar to those of a liquid-covered area (Clark et al., 2010). This hypothesis of a partially liquid-covered flat-floored depression is supported by the terrestrial analog that will be discussed in Section 6.

R2, V2 and I2 are interpreted as a past flooded area where past shorelines can be seen. Their presence is the witness of the vertical motion of the alkanofer table over the time. V3 is tentatively interpreted either as dunes, which will be compared with terrestrial analogs in Section 6, or as evaporitic deposits, following Barnes et al. (2011a). Ontario Lacus lies in an alluvial plain (I4, V4, R4b and R4d) associated with channels and small isolated lakes visible in the RADAR images. R4d and $\mathrm{R} 4 \mathrm{~b}$ differ because of their respective topography and/or rough- 
ness and/or composition. The alluvial plain is surrounded by mountains (R5), in which valleys (V6 and R6a) carry erosional products (V6 and R6b) provided by the mountains towards the eastern border of the depression.

\section{Comparison with a terrestrial analog: the Etosha Pan, Namibia}

Lorenz et al. (2010a) previously suggested an analogy between Ontario Lacus and the Racetrack Playa ephemeral lake in the Death Valley National Park (USA) due to similar flat topography of the depression and expected climate. However, the Racetrack Playa, $4 \mathrm{~km}$-long and $2.5 \mathrm{~km}$-wide, is significantly smaller than Ontario Lacus. Furthermore, it is located on the floor of a 5 to $6 \mathrm{~km}$-wide closed valley bordered by 500 m-high mountains. Topographic slopes are therefore much steeper in the region of Racetrack Playa than around Ontario Lacus. Since surface geomorphic processes highly depend on topographic slopes and basin sizes, we discuss here the analogy with other terrestrial landforms, the sizes and slopes of which are more similar to these of Ontario Lacus. These landforms are located in the Owambo Basin (Namibia) and have already been suggested as analogs for Titan's lakes by Bourgeois et al. (2008). Landforms in the extremely flat and semi-arid Owambo Basin include a striking number of similarities (shape, size, topography of the basin in which they lie, climate) with those described above for the region of Ontario Lacus.

\subsection{Regional topography and geology}

The Owambo intracontinental sedimentary basin is the western extension of the Kalahari Basin in northern Namibia and southern Angola (Fig. 8). It is approximately circular with a diameter of $750 \mathrm{~km}$. Its topographic surface is an extremely smooth and flat alluvial plain, with elevations varying gently from $1080 \mathrm{~m}$ in its southern central part to $1350 \mathrm{~m}$ at its periphery. An endorheic hydrological network drains the outer parts of this alluvial plain towards its southern central part (Marsh \& Seely, 1992; Christelis \& Struckmeier, 2001; Mendelsohn et al., 2002; Miller et al., 2010).

The Owambo Basin is filled with poorly consolidated Cretaceous and Cenozoic aeolian, lacustrine and fluviatile clays, silts and sandstones of the Kalahari formation. These sediments have a maximal thickness of 300 meters in the central part of the basin, and they decrease in thickness toward the periphery. They rest on a basement composed of consolidated Precambrian to Jurassic sedimentary and volcanic rocks overlying Precambrian metamorphic rocks. The basement crops out in various mountain ranges, up to 1600 meters in elevation, that encircle the southern, western and northern parts of the basin (Miller, 1997). Wide pediments composed of erosional products from these mountain ranges have developed along the borders of the sedimentary basin.

In the southern part of the Owambo Basin, a superficial layer of soluble calcrete, a few tens of meters in maximal thickness, covers the surface of the Kalahari sediments. This calcrete layer has formed by evaporation of groundwater and precipitation of dissolved calcium carbonate in the pore space of the Kalahari sediments and at their surface. The thickness of this calcrete layer decreases northward across the basin, because the calcium required for its formation is provided mostly by groundwaters circulating from the calcareous and dolomitic Precambrian basement of the Otavi mountain range, south of the basin, towards the central part of the basin (Christelis \& Struckmeier, 2001; Miller et al., 2010).

The extremely flat topography of the Owambo Basin (regional slope gradients of $200 \mathrm{~m}$ over more than $500 \mathrm{~km}$ ) is very similar to that of the plain around Ontario Lacus (regional slope gradients of $200 \mathrm{~m}$ over more than $330 \mathrm{~km}$ ). The Owambo Basin is also similar to the plain around Ontario Lacus in that it is drained by an endoreheic hydrographic network converging towards its central part and surrounded by basement mountains projecting a few hundreds meters above the plain and their associated pediments (Fig. 8). The cross-sectional geology of the Owambo Basin (Fig. 8b) is also very similar to the crosssectional geology inferred from our interpretative geomorphological map of the region of Ontario Lacus (Fig. 7).

\subsection{Climate and hydrogeology}

The climate over the Owambo Basin is arid to semi-arid, with an average annual rate of potential evapotranspiration (comprised between 2100 and $2500 \mathrm{~mm} / \mathrm{yr}$ ) that greatly exceeds the average annual rate of rainfall (comprised between 300 and 550 mm/yr) (Marsh \& Seely, 1992; UNEP, 1992; Mendelsohn et al., 2002). During rainfalls, as much as $83 \%$ of the water falling on the ground directly evaporates back into the atmosphere, 15 $\%$ infiltrates the ground towards the aquifer and $2 \%$ runs in the surface hydrographic network. From the $15 \%$ that infiltrates the ground, $14 \%$ is evapotranspirated back into the atmosphere later and $1 \%$ percolates through the underground aquifer and eventually reaches the hydrographic network (Marsh \& Seely, 1992). As a conclusion, only $3 \%$ of the total amount of rainfall ultimately circulates in the hydrographic network.

These climatic and hydrogeological conditions have striking similarities with those that can be expected at Ontario Lacus. Modeling of hydrocarbon condensation and rainfalls in Titan's atmosphere (Toon et al., 1988; Lorenz, 1993, 2000; Tokano et al., 2001; Rannou et al., 2006; Graves et al., 2008; Mitchell et al., 2009), morphological comparisons of channels observed on Titan's surface with terrestrial flash floods channels and desert washes (Lorenz et al., 2008a), and observations of rapid surface changes associated with cloud activity (Turtle et al., 2011b) consistently suggest that torrential rainstorms of liquid hydrocarbons may occur sporadically on Titan (Brown et al., 2010).

Mitri et al. (2007) computed a rough estimate of the precipitation rate on Titan's surface equal to $40 \mathrm{~mm}$ per Earth year. Based on the ethane photochemical production rate estimated by Atreya et al. (2006), Graves et al. (2008) computed even smaller precipitation rates (comprised between $0.63 \times 10^{-4}$ and $5 \mathrm{~mm}$ per Earth year). On the other hand, evaporation rates have been estimated to be comprised between $10 \mathrm{~mm}$ (Lorenz \& Sotin, 2010) and $10^{4} \mathrm{~mm}$ (Mitri et al., 2007) per Earth year. Though these values are still rough estimates (because of the 


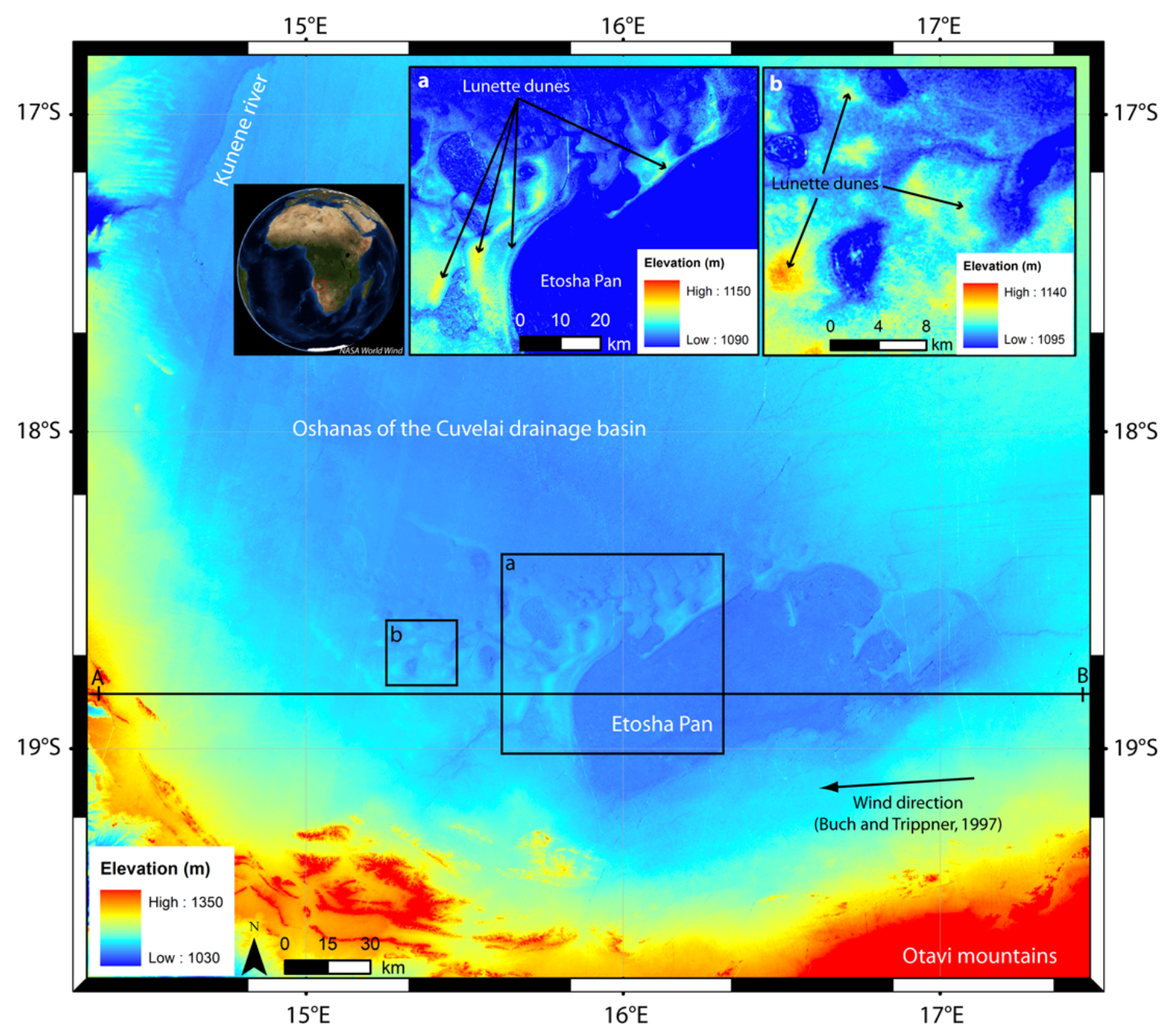

b)

\section{Geological cross-section of the Owambo Basin}

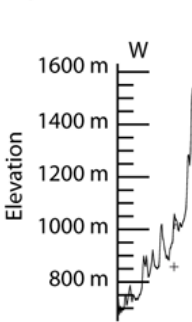

\section{Otavi mountains} (vertical exaggeration $\times 100$ )

\section{Caption:}

$\left.\begin{array}{l}\text { Aeolian sediments } \\ \text { Calcrete layer } \\ \text { Clays + sands + silts }\end{array}\right] \begin{gathered}\text { Kalaharic \& Quaternary } \\ \text { Cretaceous \& Cenozoic }\end{gathered}$

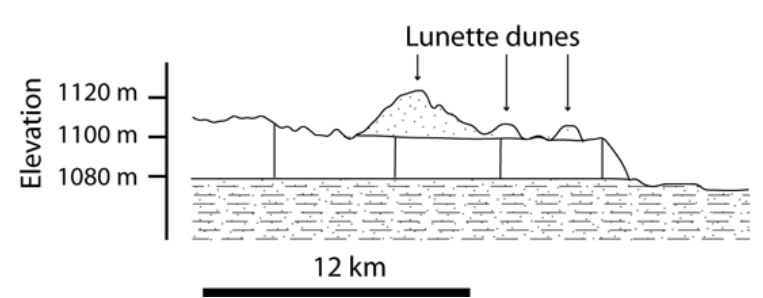

Figure 8: a) Digital Elevation Model of the Etosha region derived from Advanced Spaceborne Thermal Emission and Reflection Radiometer (ASTER) data. Elevation difference between pan floors and the regional topographic surface of the Owambo basin is at most few meters. b) Geological E-W cross-section across the Owambo basin and the Etosha Pan (vertical exaggeration: $\times 100$ ). Pans are flat-floored depressions developed at the expense of a superficial calcrete layer covering poorly consolidated sediments of the Kalahari formation. The water table rests generally close to the base of the calcrete layer and below pan floors. Lunette dunes appear as topographic ridges, a few meters high and a few hundred meters wide, located downwind from the western border of pans. 
misunderstanding on key parameters such as the lake liquid exact composition and the influence of surface winds), they are consistent with the hypothesis that potential evaporation rates exceed precipitation rates in many regions of Titan. Hence the hydrocarbon cycle at Ontario Lacus is somehow similar to the water cycle that exists in arid to semi-arid regions of the Earth such as the Owambo Basin, but with longer timescales.

\subsection{Landforms: pans, lunette dunes, shorelines, channels and deltas}

The southern part of the Owambo Basin is dotted with dozens of so-called pans: these are closed, steep-sided, flat-floored depressions with lobate contours, one to tens of kilometers wide and a few meters deep at most. The largest pan, namely the Etosha Pan, is as large as $120 \mathrm{~km}$ in length and $60 \mathrm{~km}$ in width, but it is only 15 to $20 \mathrm{~m}$ in depth relative to the surrounding plain (Fig. 8). It is similar to Ontario Lacus in shape and in size (Figs. 7 and 8).

Pan floors are extremely smooth, silty, clayey and evaporitic surfaces. Relict rounded boulders of calcrete resting on these floors in the outer parts of pans provide evidence that pans have developed at the expense of the calcrete layer, by radial regressive dissolution of their borders (Lowenstein \& Hardie, 1985; Shaw \& Thomas, 2000; Bourgeois et al., 2008; Miller et al., 2010). This interpretation is consistent with the facts that pans have formed only in those portions of the Owambo Basin where the calcrete layer is present and that pan floors are generally located at the same elevation as the base of the calcrete layer.

Throughout most hydrological years, the underground water table lies a few decimeters to a few meters below pan floors (Christelis \& Struckmeier, 2001). These therefore remain exposed and dry for decades. Only during exceptionally wet years with heavy rainfalls over the Owambo Basin does the underground water table rise a few centimeters above the topographic surface in the lowest parts of the pans, thus covering these parts with a few centimeters of surface water (Christelis \& Struckmeier, 2001). Even during these scarce flooding episodes, wide regions of pan floors remain exposed and dry or at most wet, because they stand topographically a few decimeters above the rest of the pan floors.

The shape of most pans is asymmetric: their upwind eastern contour is either concave, sinuous or triangular, whereas their downwind western contour is smooth and convex. This asymmetry is comparable to the asymmetry of Ontario Lacus contours. It has been attributed to some effects of winds on the development of pans (Goudie \& Wells, 1995).

Downwind from their western edges, most pans are bordered by lunette dunes; these are linear accumulations of aeolian sediments provided by wind deflation over desiccated pan floors (Goudie \& Wells, 1995; Marker \& Holmes, 1995; Buch \& Trippner, 1997; Shaw \& Thomas, 2000). Lunette dunes are generally arranged in sets of ridges parallel to pan edges, a few meters high at most and a few hundred meters wide, resting on the calcrete layer that borders the pans (Fig. 8). These dunes are similar in cartographic shape, in size and in location, to V3 along the eastern border of Ontario Lacus.

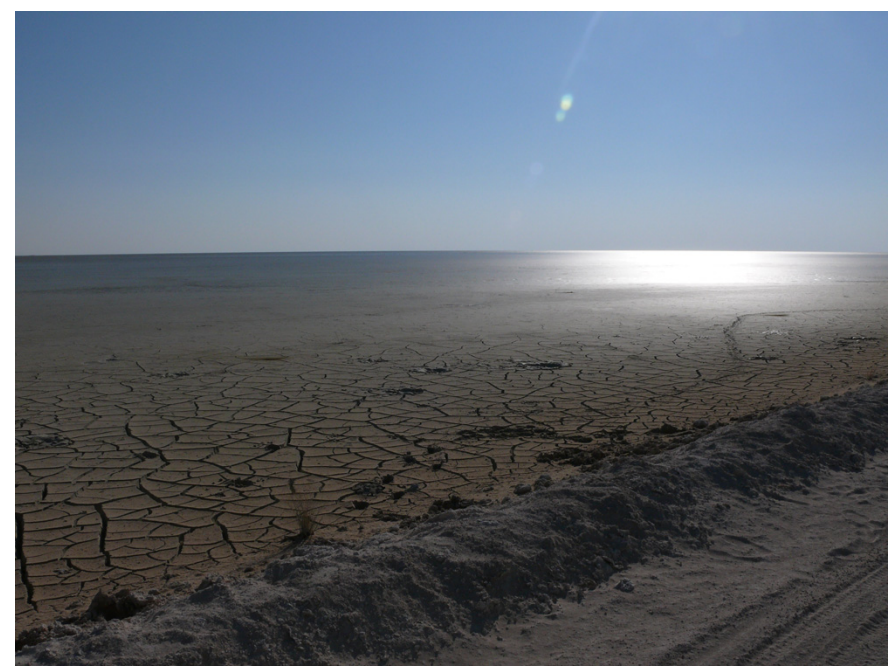

Figure 10: Exposed floor of the Etosha Pan during the dry season in July 2008. A specular reflection can be seen, even though the pan is not covered by a liquid layer. Credits: LPGNantes.

Sets of concentric lines, barely discernible in the topography but underlined by vegetation, are located between the floor of the Etosha Pan and the lunette dunes of its western border. These closely resemble lines visible in RADAR images of Ontario Lacus (R2l) and have been interpreted as past shorelines bearing witness of extreme flooding events that covered the whole area of the pan in the past (Hipondoka, 2005; Miller et al., 2010).

The alluvial plain around the Etosha Pan is drained by channels, locally named oshanas, a few meters deep and a few hundred meters wide. These channels form a dense network in the northern part of the basin and are much scarcer in its southern part. As for the pans, they are generally dry and their floors are exposed. Only during heavy rainfalls do they fill up and drain surface waters towards the Etosha Pan (Marsh \& Seely, 1992; Christelis \& Struckmeier, 2001; Mendelsohn et al., 2002; Miller et al., 2010). These channels might constitute good analogs for channels visible in RADAR images on the alluvial plain surrounding Ontario Lacus (R4).

Peninsulas are visible at the junction between some oshanas and the Etosha Pan. These are parts of delta lobes composed of sediments provided by oshanas during flooding events (Hipondoka, 2005; Miller et al., 2010). They are strikingly similar in shape to peninsulas visible along the western and eastern borders of Ontario Lacus, which have also been interpreted as delta lobes by Wall et al. (2010).

\subsection{Cross-comparison of infrared and radar images over the Etosha pans}

Figure 9a shows a MODerate resolution Imaging Spectroradiometer (MODIS) RGB color composite image of the Etosha Basin acquired in October 2004. MODIS acquires images in 36 bands ranging from 0.4 to $14.4 \mu \mathrm{m}$ with a theoretical spatial resolution comprised between $500 \mathrm{~m}$ (spatial sampling equal to $250 \mathrm{~m} /$ pixel) and $2 \mathrm{~km}$ (spatial sampling equal to $1 \mathrm{~km} /$ pixel). Channels used to produce the image presented in Fig. 9a are: 
a) (October 24th 2004)

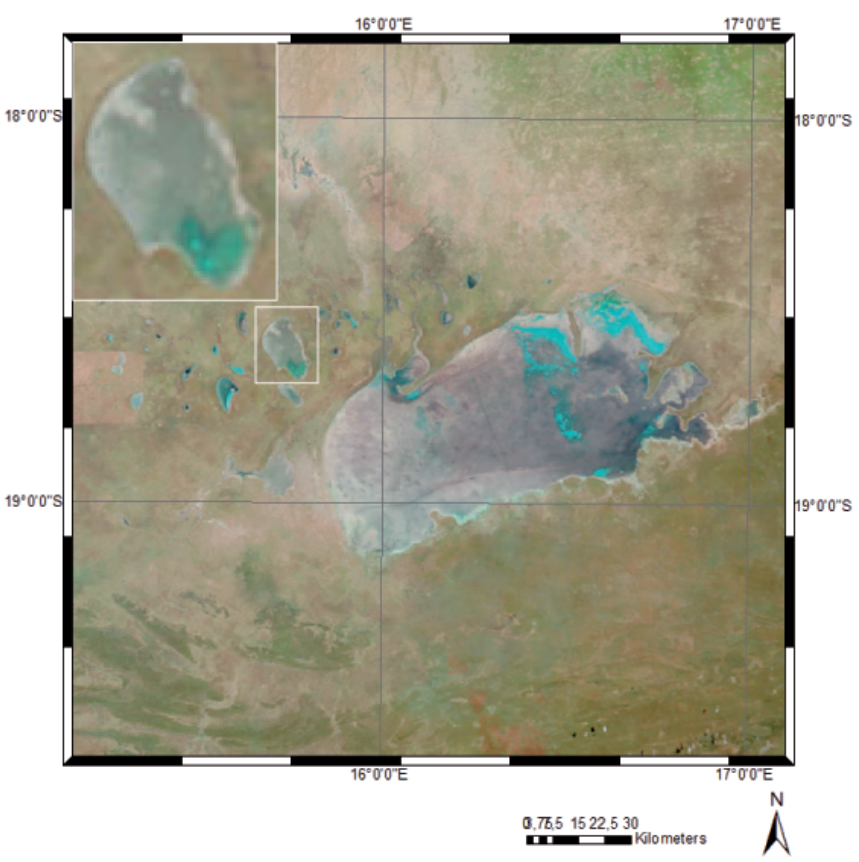

b) Envisat ASAR image acquired during the dry season (October 24th 2004)

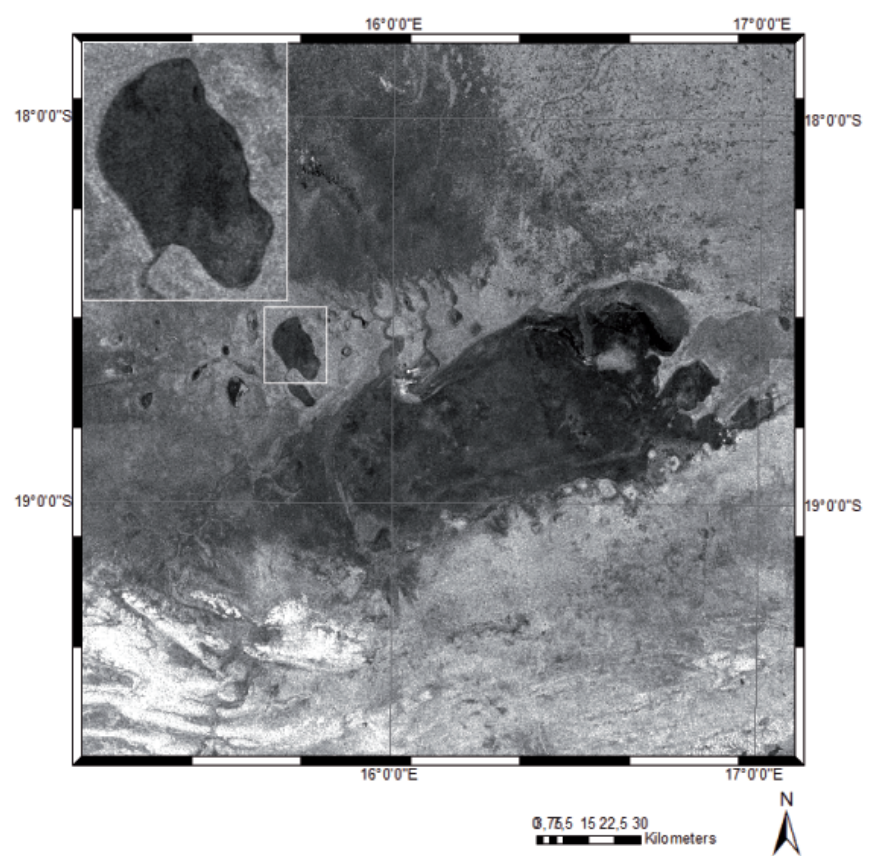

Figure 9: Liquid-coverage of the Etosha pans. a) MODIS image (R: $2.1 \mu \mathrm{m}, \mathrm{G}$ : $0.8 \mu \mathrm{m}, \mathrm{B}: 0.6 \mu \mathrm{m})$ taken on October 24th 2004. Blue areas correspond to flooded regions. A local zoom on the Natukanaoka Pan is shown as an inset in both the radar and infrared images. These zooms illustrate well the general smoothness of pans floors. b) Radar Envisat ASAR image showing topography, roughness, dielectric constant contrasts between the Etosha region terrains on the same day at the end of the dry season. Smooth terrains are dark (pan floors, oshanas) whereas rough terrains are grey and mountainous regions are white. Credits: ASAR, data provided by the European Space Agency (C) ESA 2009, ESA ®); MODIS, data provided by the National Aeronautics and Space Agency NASA/GSFC, MODIS Rapid Response.

band 7 (from 2.105 to $2.155 \mu \mathrm{m}$ ) as red, band 2 (from 0.841 to $0.876 \mu \mathrm{m}$ ) as green and band 1 (from 0.620 to $0.670 \mu \mathrm{m}$ ) as blue. With this band combination, blue regions in the images correspond to free water (and also clouds if present). In October 2004, the Etosha Pan is almost dry, showing only very localized areas covered by water in its deepest parts (due to rainfalls in September and October 2004). Most of the other pans are almost dry. The Natukanaoka Pan, located northwest of the Etosha Pan (zooms displayed in insets on Fig. 9), contains water only in its southern part.

Figure 9b shows an Envisat Advanced Synthetic Aperture Radar (ASAR) image of the same area acquired the same day. ASAR acquires images in C-band $(\lambda=5.66 \mathrm{~cm}, f=5.3 \mathrm{GHz})$ with a spatial resolution of $150 \mathrm{~m}$ (spatial sampling equal to $75 \mathrm{~m} / \mathrm{pixel}$ ) and an incidence angle varying from $28^{\circ}$ to $41^{\circ}$. This image is in $\mathrm{HH}$ polarization and has been acquired with an ascending pass. Pans appear dark in this image as is well exemplified by the two widest pans: the Etosha Pan and the Natukanaoka Pan. This is due to the fact that their floors are smooth over their whole extent at the RADAR wavelength, even though they are not covered by a liquid layer. This smoothness of pan floors is illustrated in Fig. 10, which is a picture taken along the Etosha Pan border in July 2008, and where a specular reflection is seen on the exposed pan floor.

The composition of surface materials differs between the Earth and Titan. Therefore, the respective signatures of liquids and solids on radar and infrared images undoubtedly differ be- tween the Earth and Titan. These issues are discussed in details in Sections 7.1 and 7.2. Still, the comparison between optical and radar satellite images of the Owambo Basin illustrates the fact that smooth solid surfaces composed of silts and clays, such as those of exposed pan floors, can appear as dark as liquid surfaces in SAR images even though they are not covered by liquids. This kind of smooth and fine-grained surface materials might constitute relevant analogs for the Unit B in Ontario Lacus, as previously mentioned by Lorenz et al. (2008b) to explain some river channels and by Lorenz et al. (2010a) with the comparison between Ontario Lacus and the Racetrack Playa.

Channels and depressions are visible on the exposed pan floors on both MODIS and ASAR images (Fig. 9). These might constitute relevant analogs for channels and depressions observed both on VIMS and RADAR images on the floor of Ontario Lacus (Fig. 4), which underline the fact that Ontario Lacus is exposed over half its surface area (R11) and covered by a thin liquid layer in its deepest parts (R1d).

\section{Discussion}

\subsection{Entire or partial coverage of Ontario Lacus' floor?}

Hayes et al. (2010) suggested a geomorphological interpretation, consistent with SAR and altimetry RADAR data, whereby the floor of Ontario Lacus is entirely covered by simple liquid light hydrocarbons. They tentatively determined its nearshore bathymetry and liquid loss tangent (found to be consis- 

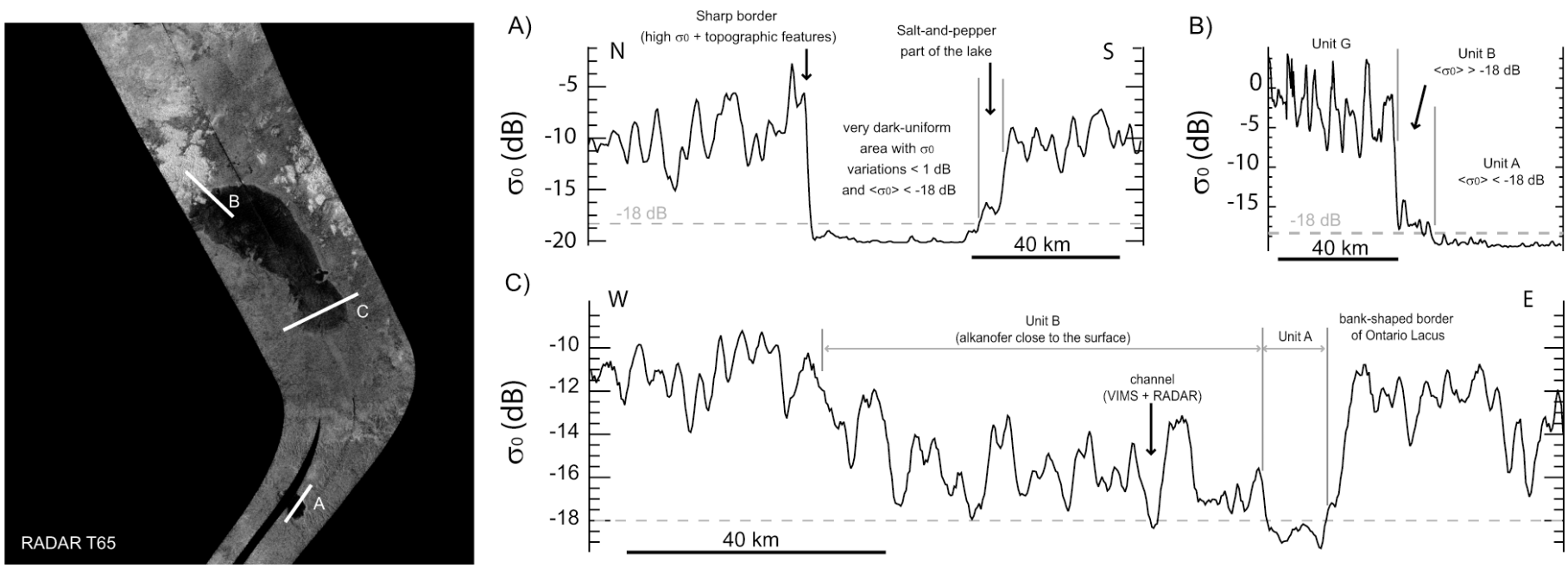

C)

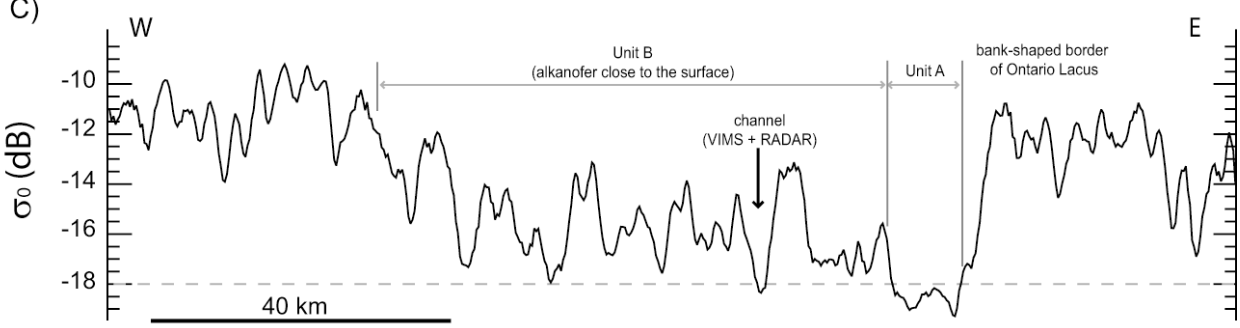

Figure 11: Radar backscatter cross-section profiles over Ontario Lacus' region A. Profile A illustrates the radar signature of a steep-sided liquid filled lake. The areas uniformly dark have $\sigma^{0}$ values lower or equal to $-18 \mathrm{~dB}$. This value is thus interpreted as the transition between a probably soggy area and a liquid-covered area. Profile B illustrates the signal recorded in the northern part of Ontario Lacus and profile C illustrates the signal recorded in its southern part. The channel seen in VIMS and RADAR data appears as liquid-covered. Units A, B and G refer to the geomorphological units defined in Fig. 7.

tent with a composition dominated by liquid hydrocarbons) under the following assumptions: (1) there is no break-in-slope at the shoreline of Ontario Lacus, (2) the real part of the liquid dielectric constant is equal to that of Liquefied Natural Gas (LNG) measured by Paillou et al. (2008b) (i.e. $\epsilon^{\prime}=1.75$ ); and (3) the observed exponential decay results from the absorption of microwaves by a liquid medium that deepens linearly with distance from the local shoreline.

However, the composition of surface liquids and solids on Titan is still a matter of intense debate, on both theoretical (Dubouloz et al., 1989; Mitri et al., 2007; Cordier et al., 2009) and observational (McCord et al., 2006; Brown et al., 2008; McCord et al., 2008; Clark et al., 2010; Moriconi et al., 2010) grounds. In particular, the liquids may be much more complex than simple light hydrocarbons and may include several dissolved compounds (see Section 7.3) (Dubouloz et al., 1989; Raulin, 2008; Cordier et al., 2009; Lorenz et al., 2011), suspended particles such as tholins formed in Titan's atmosphere (Khare et al., 1984; Israel et al., 2005; Carrasco et al., 2009), or other complex molecules (Clark et al., 2009; Lorenz et al., 2011). Laboratory measurements of the dielectric properties of these complex materials are still lacking, but they are potentially much more absorbing to microwaves than simple light hydrocarbons (Sen et al., 1992).

Based on a terrestrial analog, we suggest here an alternative geomorphological interpretation where Ontario Lacus is a flat depression lying in a flat sedimentary basin. This interpretation does not require any assumption on the composition of liquids and solids at the surface of Titan. According to our interpretation, Unit A (corresponding to the darkest parts of Ontario Lacus in RADAR images, R1d), is covered by liquids because the radar backscatter recorded over this unit is below the noiselevel, and likely attributable to a combination of specular reflection and absorption in these liquids. This hypothesis is inconsistent with a composition dominated by simple liquid light hydrocarbons according to the penetration depth of microwaves in these materials (Paillou et al., 2008b; Hayes et al., 2010) or requires that the liquid layer is deep enough so that microwaves do not probe the floor. However, it might be consistent with more complex liquid compositions, involving dissolved or suspended materials.

By contrast, Unit B (corresponding to brighter areas on RADAR images, R11) is interpreted as the flat exposed floor of Ontario Lacus because channels are visible in this unit on both RADAR and VIMS images acquired at different dates. Consistent with this interpretation is the fact that the average radar backscatter over R11 is low but not null (Fig. 11). This low residual radar backscatter is attributable to quasi-specular reflection on Ontario Lacus' floor or to volume scattering of microwaves in the subsurface below this floor. The diagnostic salt-and-pepper texture of these areas is attributable to speckle noise. Speckle noise is produced by mutually interfering electromagnetic waves that are scattered off of a surface that is rough on the order of the wavelength and by coherent interferences between scattering centers in a volume (Hayes et al., 2010). It can thus be indicative of the surface roughness and of the degree of volume scattering of an area. This texture appears in exactly the same regions, where the average radar backscatter is low but not null, in two images (T57-58 and T65) separated by a 6 months interval, and acquired with different viewing geometries. On the other hand, R1d displays this texture neither in T57-58 nor in T65. Since speckle noise is an effect of the observed surface roughness and subsurface volume scattering, not an instrumental effect (Hayes et al., 2010), the lack of speckle noise on Unit A leads us to conclude that the salt-and-pepper texture observed on Unit B is characteristic of a specific geomorphological unit different from Unit A. Roughness on the order of the wavelength or significant volume scattering compared to that of Unit A could explain this difference between Units A and B. 

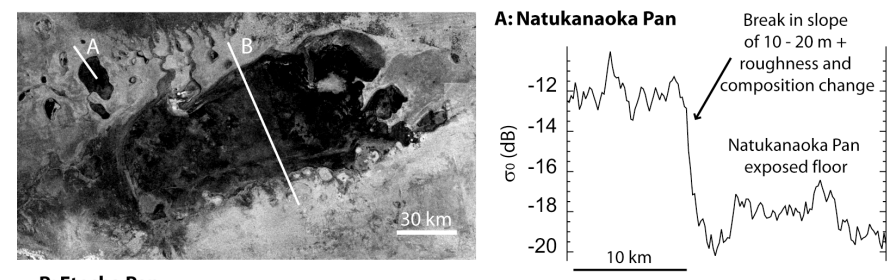

B: Etosha Pan

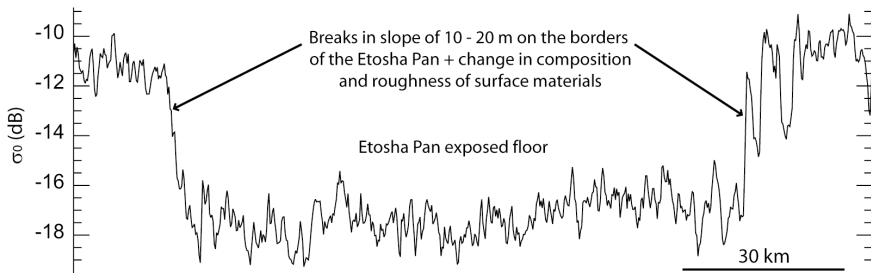

Figure 12: Influence of the break in slope and change in composition and roughness of surface material between the alluvial plain and the exposed pan floors (for the Natukanaoka Pan and the Etosha Pan) on the radar backscatter crosssection. Credits: ASAR, data provided by the European Space Agency (C) ESA 2009, ESA $®$, image of the 24th October 2004.

According to our interpretation, the exponential decrease in average radar backscatter observed by Hayes et al. (2010) across the outer border of Unit B (Fig. 11) cannot be attributed to microwave attenuation through a deepening liquid medium. A similar decrease in radar backscatter is observed across the border of the Etosha Pan and the Natukanaoka Pan, at the topographic break-in-slope located between the alluvial plain and the exposed pan floors (Fig. 12). Therefore we suspect that differences in roughness, elevation, slope and composition (dielectric constant and microwave attenuation rate) between rough solid materials surrounding Ontario Lacus (Units $\mathrm{C}$ to $\mathrm{F}$ ) and smoother (but still not liquid) materials covering its floor (Unit B) might explain the observed exponential decrease. Since surface materials are different on Titan and on Earth however, it is difficult to evaluate whether the decay observed at Ontario has the same origin as that observed at Etosha. When more constraints on the nature of Titan surface materials and on their dielectric properties are made available, it will be possible to assess more clearly the geomorphological significance of this decay, by modeling radar backscatter across a break-in-slope between two different solid materials located at two different elevations and with two different roughnesses.

It should be noted that Wye et al. (2009) constrained the RMS surface height to be less than $3 \mathrm{~mm}$ over Units A and B and attributed such a smoothness to the presence of a quiescent liquid body covering the whole surface area of Ontario Lacus. However, according to our interpretation, the depression would not be fully covered by liquids, thus exposing a floor with a roughness lower than $3 \mathrm{~mm}$. On Earth, such a surface roughness can easily be reached in semi-arid/arid environments according to measured mean RMS surface heights of depression floors that can be millimeter to sub-millimeter scale (Archer \& Wadge, 2001; Shepard et al., 2001).

\subsection{Thickness of liquid coverage}

The behavior of liquids and solids on Titan differs from that on Earth, and particularly at radio wavelengths. Liquid water on Earth has a high dielectric constant $\left(\varepsilon_{\mathrm{H}_{2} \mathrm{O}} \simeq 53.98+34.38 i\right)$, which results in an extremely small penetration depth through a pure liquid water layer, of only few millimeters (ASCAT, 2005). On the other hand, liquid hydrocarbons potentially present on Titan's surface have dielectric constants much smaller than that of liquid water $\left(\varepsilon_{L N G} \simeq 1.75+0.002 i\right)$, which result in a penetration depth of few meters depending of the nature of the liquid (Paillou et al., 2008a,b). A similar penetration depth is also found in case of Titan's relevant solid materials (Paillou et al., 2008a).

Only the dielectric properties of simple liquid hydrocarbons have been measured so far, and these do not include more complex compounds, dissolved or still under their particulate form, trapped into the liquids. These latter compounds could be responsible for less "transparent" and more absorbing liquids (Sen et al., 1992). In doing so, a "thick" liquid layer would not be required to explain the quasi absence of radar signal in Unit A, while a small radar signal is recorded in Unit B. According to our interpretation, a thin liquid layer covering Unit A, the composition of which is much more complex than simple liquid hydrocarbons previously considered (Paillou et al., 2008b; Hayes et al., 2010), would pertain to Ontario Lacus.

\subsection{Implications for surface processes and climate}

If the geomorphological analogy between Ontario Lacus and the Etosha Pan is valid, a number of conclusions can be drawn on the geomorphological, hydrological and climatic significance of Ontario Lacus. This comparison implies that the alkanofer table would exist close to the topographic surface below Ontario Lacus and its alluvial plain (Fig. 7), which is consistent with Hayes et al. (2008) model of Titan's lakes. Small elevation differences in this environment would result in the presence of only restricted areas covered by liquids where the alkanofer table would stand above the topographic surface (Unit A in Fig. 7 ), the underlying medium being saturated by liquids. These liquid-covered areas are expressed as the liquid-covered portion of Ontario Lacus as well as small secondary lakes and channels.

The "hydrological" regime of Ontario Lacus would thus be dominated by the vertical motion of the alkanofer table rather than by surface runoff. This inference is consistent with the lack of organized "hydrographic network" at the surface of the alluvial plain and with the model developed by Hayes et al. (2008) describing interactions of the liquid with the subsurface. Past flooded areas (Unit C) would thus witness past high-stand levels of the alkanofer, as previously hypothesized by Barnes et al. (2009).

The Namibian pans are topographic depressions formed at the expense of a surface evaporitic layer composed of calcretes, a soluble material at geological timescales. Bourgeois et al. (2008) previously suggested that similar surface dissolution processes could pertain to other lakes of smaller sizes in Titan's northern hemisphere. The soluble surface layer could result from the crystallization of the chemical compounds dissolved in the alkanofer during the evaporation of the liquids, 
in a way similar to the development of the Namibian calcrete layer (Bourgeois et al., 2008). This hypothesis requires potential evaporation rates greater than precipitation rates and therefore climatic conditions close to those encountered in semi-arid regions on Earth. This is consistent with climatic models and models of liquid hydrocarbon stability at the surface of Titan in the near polar regions (Section 6.2).

An alternative mechanism to develop such a soluble surface layer would be the accumulation by precipitation on the ground of soluble compounds formed in the atmosphere. The estimated precipitation rates of some solid compounds supposedly implied in Titan's atmospheric chemistry support this hypothesis (Lavvas et al., 2008a,b; Vuitton et al., 2008; Cordier et al., 2009). Soluble compounds implied in dissolution/crystallization and precipitation processes could include hydrogen cyanide, butane, acetylene, acetonitrile, carbon dioxide and benzene (Cordier et al., 2009).

Potential detection of some of these compounds from the orbit by VIMS (Clark et al., 2010; Moriconi et al., 2010) and identification on the ground thanks to the GCMS instrument onboard the Huygens probe (Niemann et al., 2005, 2010) gives further credence to this scenario of Ontario Lacus' development by dissolution. Given this background, a plausible scenario for the development of Ontario Lacus would thus be a combination of both mechanisms with (1) formation of a soluble surface layer due to precipitation on the ground of soluble compounds formed in the atmosphere; (2) raising of the alkanofer table above the topographic surface of the depression during rainy events and dissolution on its borders and (3) evaporation of the liquids and crystallization of the dissolved compounds ontop the substratum (formation of the soluble surface layer) and in its pores.

\section{Conclusion}

We introduced a new method to mitigate atmospheric backscattering effects in VIMS images of Titan's surface. The method has been applied to VIMS cubes of Ontario Lacus, a lake located at high southern latitudes, where strong backscattering by the aerosols occurs due to extreme viewing geometries.

We propose that Ontario Lacus is an extremely flat and smooth depression similar to the Etosha Pan in Namibia. Both depressions are located in alluvial plains in which evaporation rates are greater than precipitation rates, making the liquids unstable at the surface. In the Etosha region, the only way to sustain some liquids in the depression is to raise the water table above the topographic surface during flooding events. In doing so, the pan expands by dissolution of a surface layer composed of calcretes, a soluble rock at geological timescales. During the evaporation of the liquid water, calcium carbonates crystallize in the pore of a substratum composed of sand, silts and clays, and at the surface, thus maintaining the existence of the calcrete layer.

The methane-ethane table would have an analogous behavior on Titan, thus explaining the joint observation of the radar-dark (liquid-covered floor) and the radar-brighter (wet exposed floor) areas in Ontario Lacus. The depression also appears dark in the infrared data, which implies that the top few microns of its exposed floor consist of absorbing materials and most probably a liquid-saturated substratum. The observation of channels on the depression floor both in infrared and radar data acquired at a 2years time interval supports our interpretation in which Ontario Lacus' floor is only partially covered by liquids. The presence of shorelines around Ontario Lacus argues for past liquid highstand levels. The nature of the materials along the smooth convex downwind border of the depression, seen in imagery and altimetry data is more hypothetical. It is tentatively interpreted as lunette dunes similar to those located on the downwind border of the Etosha pans. Their presence argues for periods of drying and aeolian deflation of Ontario Lacus' floor. Another explanation could be that it is evaporitic deposits, by analogy with recent observations of northern polar lakes (Barnes et al., 2011a). Both hypotheses are consistent with Titan's "semi-arid" climate settings in these regions.

The comparison with the Etosha Pan suggests that Ontario Lacus formed due to dissolution processes analogous to those encountered in Namibia. A soluble surface layer would therefore develop ontop a saturated substratum over geological timescales. The existence of such a surface layer is supported by the presence of several potential solutes in Titan's lakes that could crystallize when the liquids evaporate. This surface layer is also supported by estimates of precipitation rates on the ground of soluble compounds synthesized in the atmosphere. Potential remote detection by VIMS and identification in situ by the GCMS instrument of some of these compounds also agree with this scenario.

According to this interpretation, Ontario Lacus would not be covered by a thick liquid layer only composed of light hydrocarbons. A thin liquid layer with a more complex composition, including solutes and/or suspended particles, could be able to reduce the penetration depth of the RADAR microwaves and explain the quasi total absence of signal in the darkest parts of Ontario Lacus (Unit A - Fig. 7), without invoking a liquid coverage by a thick liquid layer. Since the alkanofer should be close to the topographic surface, the underlying substratum is most probably saturated by liquids, thus yielding to an optical and microwave absorbing exposed floor (Unit B - Fig. 7). The signal recorded by the RADAR instrument in these portions of Ontario Lacus could result from backscattering from a rougher exposed surface than that of the liquids and/or could be attributed to volume scattering if the penetration depth is sufficient. The transition between the interior and the exterior of Ontario Lacus is interpreted as a small change in elevation and a change in roughness and/or composition of solid surface materials between Ontario Lacus' exposed floor and the alluvial plain. Comparison between the radar signal recorded over Ontario Lacus and that recorded on another Titan's lake, south of Ontario Lacus (Fig. 11), and on the pans of the Owambo Basin, are in agreement with this interpretation. 


\section{Acknowledgments}

The authors want to thank Stephen Wall, Alexander Hayes and an anonymous reviewer for useful comments on the manuscript, and appreciate financial support provided by CNES (France), the Institut National des Sciences de l'Univers (INSU Programme National de Planétologie and Programme Reliefs, France) and the Agence Nationale de la Recherche (ANR project Exoclimat, France). ASTER GDEM is a product of METI and NASA. The Envisat ASAR image has been provided by the European Space Agency (CESA 2009, ESA®. The MODIS image has been provided by the National Aeronautics and Space Agency NASA/GSFC, MODIS Rapid Response.

\section{References}

Archer, D. J., \& Wadge, G. (2001). Modeling the backscatter response due to salt cry development. IEEE Transactions on Geoscience and Remote Sensing, 39, 2307-2310.

ASCAT (2005). Definition of Quality Flags. Technical Report Vienna University of Technology, Institute of Photogrammetry and Remote Sensing. ASCAT Soil Moisture Report Series No. 7.

Atreya, S. K., Adams, E. Y., Niemann, H. B., Demick-Montelara, J. E., Owen, T. C., Fulchignoni, M., Ferri, F., \& Wilson, E. H. (2006). Titan's methane cycle. Planetary and Space Science, 54, 1177-1187.

Barnes, J. W., Bow, J., Schwartz, J., Brown, R. H., Soderblom, J. M., Hayes, A. G., Vixie, G., Moulic, S. L., Rodriguez, S., Sotin, C., Jaumann, R., Stephan, K., Soderblom, L. A., Clark, R. N., Buratti, B. J., Baines, K. H., \& Nicholson, P. D. (2011a). Organic Sedimentary Deposits in Titan's Dry Lakebeds: Probable Evaporite. Icarus, 216, 136 - 140.

Barnes, J. W., Brown, R. H., Soderblom, J. M., Soderblom, L., Jaumann, R., Jackson, B., Le Mouélic, S., Sotin, C., Buratti, B. J., Pitman, K. M., Baines, K. H., Clark, R. N., Nicholson, P. D., Turtle, E. P., \& Perry, J. (2009). Shoreline features of Titan's Ontario Lacus from Cassini/VIMS observations. Icarus, 201, $217-225$.

Barnes, J. W., Brown, R. H., Soderblom, L., Buratti, B. J., Sotin, C., Rodriguez, S., Le Mouélic, S., Baines, K. H., Clark, R., \& Nicholson, P. (2007). Globalscale surface variations on Titan seen from Cassini/VIMS. Icarus, 186, 242 -258 .

Barnes, J. W., Soderblom, J. M., Brown, R. H., Soderblom, L. A., Stephan, K., Jaumann, R., Moulic, S. L., Rodriguez, S., Sotin, C., Buratti, B. J., Baines, K. H., Clark, R. N., \& Nicholson, P. D. (2011b). Wave constraints for Titan's Jingpo Lacus and Kraken Mare from VIMS specular reflection lightcurves. Icarus, 211, $722-731$.

Bourgeois, O., Lopez, T., Le Mouélic, S., Fleurant, C., Tobie, G., Le Corre, L., Le Deit, L., Sotin, C., \& Bodeur, Y. (2008). A surface dissolution/precipitation model for the development of lakes on Titan, based on an arid terrestrial analogue: The pans and calcretes of Etosha. In Lunar and Planetary Science XXXIX (p. 1733).

Brown, R. H., Baines, K. H., Bellucci, G., Bibring, J. P., Buratti, B. J., Capaccioni, F., Cerroni, P., Clark, R. N., Coradini, A., Cruikshank, D. P., Drossart, P., Formisano, V., Jaumann, R., Langevin, Y., Matson, D. L., McCord, T. B., Mennella, V., Miller, E., Nelson, R. M., Nicholson, P. D., Sicardy, B., \& Sotin, C. (2004). The Cassini Visual And Infrared Mapping Spectrometer (VIMS) Investigation. Space Science Reviews, 115, 111 - 168.

Brown, R. H., Lebreton, J.-P., \& Whaite, J. H. (2010). Titan from CassiniHuygens. Springer.

Brown, R. H., Soderblom, L. A., Soderblom, J. M., Clark, R. N., Jaumann, R., Barnes, J. W., Sotin, C., Buratti, B., Baines, K. H., \& Nicholson, P. D. (2008). The identification of liquid ethane in Titan's Ontario Lacus. Nature, 454, $607-610$.

Buch, M. W., \& Trippner, C. (1997). Overview of the geological and geomorphological evolution of the Etosha region, Northern Namibia. Madoqua, 20, $65-74$.

Carrasco, N., Schmitz-Afonso, I., Bonnet, J., Quirico, E., Thissen, R., Dutuit, O., A., B., Laprévote, O., Buch, A., Giulani, A., Adandé, G., Ouni,
F., Hadamcik, E., Szopa, C., \& Cernogora, G. (2009). Chemical characterisation of Titan's tholins: Solubility, morphology and molecular structure revisited. Journal of Physical Chemistry, 113, 11195-11203.

Christelis, G., \& Struckmeier, W. (2001). Groundwater in Namibia: An explanation to the hydrological map. John Meinert Printing, Windhoek.

Clark, R. N., Curchin, J. M., Barnes, J. W., Jaumann, R., Soderblom, L., Cruikshank, D. P., Lunine, J., Stephan, K., Hoefen, T. M., Le Mouélic, S., Sotin, C., Baines, K. H., Buratti, B., \& Nicholson, P. (2010). Detection and mapping of hydrocarbon deposits on Titan. Journal of Geophysical Research, 115, E10005.

Clark, R. N., Curchin, J. M., Hoefen, T. M., \& Swayze, G. A. (2009). Reflectance spectroscopy of organic compounds: 1. Alkanes. Journal of Geophysical Research, 114, E03001.

Cordier, D., Mousis, O., Lunine, J. I., Lavvas, P., \& Vuitton, V. (2009). An estimate of the chemical composition of Titan's lakes. The Astrophysical Journal, 707, L128 - L131.

Dubouloz, N., Raulin, F., Lellouch, E., \& Gautier, D. (1989). Titan's hypothesized ocean properties: The influence of surface temperature and atmospheric composition uncertainties. Icarus, 82, $81-96$.

Elachi, C., Allison, M. D., Borgarelli, L., Encrenaz, P., Im, E., Janssen, M. A., Johnson, W. T. K., Kirk, R. L., Lorenz, R. D., Lunine, J. I., Muhleman, D. O., Ostro, S. J., Picardi, G., Posa, F., Rapley, C. G., Roth, L. E., Seu, R., Soderblom, L. A., Vetrella, S., Wall, S. D., Wood, C. A., \& Zebker, H. A. (2004). Radar: The Cassini Titan Radar Mapper. Space Science Reviews, $115,71-110$.

Ford, J. P., Blom, R. G., Bryan, M. L., Daily, M. I., Dixon, T. H., Elachi, C., \& Xenos, E. C. (1980). Seasat Views North America, The Caribbean, and Western Europe With Imaging SAR. JPL publication 80 - 67.

Goudie, A. S., \& Wells, G. L. (1995). The nature, distribution and formation of pans in arid zones. Earth-Science Reviews, 38, 1-69.

Graves, S. D. B., McKay, C. P., Griffith, C. A., Ferri, F., \& Fulchigoni, M. (2008). Rain and hail can reach the surface of Titan. Planetary and Space Science, 56, 346-357.

Hapke, B. (1981). Bidirectional Reflectance Spectroscopy 1. Theory. Journal of Geophysical Research, 86, 3039 - 3054.

Hapke, B. W. (1963). A theoretical photometric function for the lunar surface. Journal of Geophysical Research, 68, 4571-4586.

Hayes, A., Aharonson, O., Callahan, P., Elachi, C., Gim, Y., Kirk, R., Lewis, K., Lopes, R., Lorenz, R., Lunine, J., Mitchell, K., Mitri, G., Stofan, E., \& Wall, S. (2008). Hydrocarbon lakes on Titan: Distribution and interaction with an isotropic porous regolith. Geophysical Research Letters, 35, L09204.

Hayes, A. G., Aharonson, O., Lunine, J. I., Kirk, R. L., Zebker, H. A., Wye, L. C., Lorenz, R. D., Turtle, E. P., Paillou, P., Mitri, G., Wall, S. D., Stofan, E. R., Mitchell, K. L., \& Elachi, C. (2011). Transient surface liquid in Titan's polar regions from Cassini. Icarus, 211, $655-671$.

Hayes, A. G., Wolf, A. S., Aharonson, O., Zebker, H., Lorenz, R., Kirk, R. L., Paillou, P., Lunine, J., Wye, L., Callahan, P., Wall, S., \& Elachi, C. (2010). Bathymetry and absorptivity of Titan's Ontario Lacus. Journal of Geophysical Research, 115, E09009.

Hipondoka, M. H. T. (2005). The development and evolution of Etosha Pan, Namibia. Ph.D. thesis University of Wurzburg (Germany). 154pp.

Israel, G., Szopa, C., Raulin, F., Cabane, M., Niemann, H. B., Atreya, S. K., Bauer, S. J., Brun, J., Chassefiere, E., Coll, P., Conde, E., Coscia, D., Hauchecorne, A., Millian, P., Nguyen, M.-J., Owen, T., Riedler, W., Samuelson, R., Siguier, J., Steller, M., Sternberg, R., \& Vidal-Madjar, C. (2005). Complex organic matter in Titan's atmospheric aerosols from in situ pyrolysis and analysis. Nature, 438, $796-799$.

Janssen, M. A., Lorenz, R. D., West, R., Paganelli, F., Lopes, R. M., Kirk, R. L., Elachi, C., Wall, S. D., Johnson, W. T. K., Anderson, Y., Boehmer, R. A., Callahan, P., Gim, Y., Hamilton, G. A., Kelleher, K. D., Roth, L., Stiles, B., $\&$ Le Gall, A. (2009). Titan's surface at 2.2-cm wavelength imaged by the Cassini RADAR radiometer: Calibration and first results. Icarus, 200, 222 -239 .

Khare, B. N., Sagan, C., Arakawa, E. T., Suits, F., Callcott, T. A., \& Williams, M. W. (1984). Optical constants of organic tholins produced in a simulated Titanian atmosphere: From soft x-ray to microwave frequencies. Icarus, 60, $127-137$

Lavvas, P. P., Coustenis, A., \& Vardavas, I. M. (2008a). Coupling photochemistry with haze formation in Titan's atmosphere, Part I: Model description. Planetary and Space Science, 56, 27 - 66.

Lavvas, P. P., Coustenis, A., \& Vardavas, I. M. (2008b). Coupling photochem- 
istry with haze formation in Titan's atmosphere, Part II: Results and validation with Cassini/Huygens data. Planetary and Space Science, 56, 67 99.

Le Corre, L., Le Mouélic, S., Sotin, C., Combe, J.-P., Rodriguez, S., Barnes, J. W., Brown, R. H., Buratti, B. J., Jaumann, R., Soderblom, J., Soderblom, L. A., Clark, R., Baines, K. H., \& Nicholson, P. D. (2009). Analysis of a cryolava flow-like feature on Titan. Planetary and Space Science, 57, $870-$ 879

Le Mouélic, S., Cornet, T., Rodriguez, S., Sotin, C., Barnes, J. W., Brown, R. H., Baines, K. H., Buratti, B. J., Clark, R. N., \& Nicholson, P. D. (2010) Global Mapping of Titan in the infrared using a heuristic approach to deccorelate surface and atmospheric components. In IEEE Transactions on Geoscience and Remote Sensing, Hyperspectral Image and Signal Processing: Evolution in Remote Sensing, WHISPERS.

Le Mouélic, S., Paillou, P., Janssen, M. A., Barnes, J. W., Rodriguez, S., Sotin, C., Brown, R. H., Baines, K. H., Buratti, B. J., Clark, R. N., Crapeau, M., Encrenaz, P. J., Jaumann, R., Geudtner, D., Paganelli, F., Soderblom, L., Tobie, G., \& Wall, S. (2008). Mapping and interpretation of Sinlap crater on Titan using Cassini VIMS and RADAR data. Journal of Geophysical Research, 113, E04003.

Lopes, R. M. C., Mitchell, K. L., Wall, S. D., Mitri, G., Janssen, M., Ostro, S., Kirk, R. L., Hayes, A. G., Stofan, E. R., Lunine, J. I., Lorenz, R. D., Wood, C., Radebaugh, J., Paillou, P., Zebker, H., \& Paganelli, F. (2007). The lakes and seas of Titan. EOS, Transactions American Geophysical Union, 88, 569 $-576$

Lorenz, R. D. (1993). The life, death and afterlife of a raindrop on Titan. Planetary and Space Science, 41, 647 - 655.

Lorenz, R. D. (2000). Planetary Science: The Weather on Titan. Science, 290, $467-468$

Lorenz, R. D., Jackson, B., \& Hayes, A. (2010a). Racetrack and Bonnie Claire: Southwestern US playa lakes as analogs for Ontario Lacus, Titan. Planetary and Space Science, 58, 724 - 731.

Lorenz, R. D., Lopes, R. M., Paganelli, F., Lunine, J. I., Kirk, R. L., Mitchell, K. L., Soderblom, L. A., Stofan, E. R., Ori, G., Myers, M., Miyamoto, H. F., Radebaugh, J., Stiles, B., Wall, S. D., Wood, C. A., \& the Cassini RADAR Team (2008a). Fluvial channels on Titan: Initial Cassini RADAR observations. Planetary and Space Science, 56, 1132 - 1144.

Lorenz, R. D., Lunine, J. I., Grier, J. A., \& Fisher, M. A. (1995). Prediction of aeolian features on planets: Application to Titan paleoclimatology. Journal of Geophysical Research, 100, 26377 - 26386.

Lorenz, R. D., Lunine, J. I., \& Neish, C. D. (2011). Cyanide Soap? Dissolved materials in Titan's Seas. In EPSC-DPS2011 (p. 488). volume 6.

Lorenz, R. D., Mitchell, K. L., Kirk, R. L., Hayes, A. G., Aharonson, O., Zebker, H. A., Paillou, P., Radebaugh, J., Lunine, J. I., Janssen, M. A., Wall, S. D., Lopes, R. M., Stiles, B., Ostro, S., Mitri, G., \& Stofan, E. R. (2008b) Titan's inventory of organic surface materials. Geophysical Research Letters, 35, L02206.

Lorenz, R. D., Newman, C., \& Lunine, J. I. (2010b). Threshold of wave generation on Titan's lakes and seas: Effect of viscosity and implications for Cassini observations. Icarus, 207, 932 - 937

Lorenz, R. D., \& Sotin, C. (2010). The moon that would be a planet. Scientific American, 302, $36-43$

Lowenstein, T. K., \& Hardie, L. A. (1985). Criteria for the recognition of saltpan evaporites. Sedimentology, 32, $627-644$.

Marker, M. E., \& Holmes, P. J. (1995). Lunette dunes in the northeast Cape, South Africa, as geomorphic indicators of palaeoenvironmental change. Catena, 24, $259-273$

Marsh, A., \& Seely, M. (1992). Oshanas, sustaining people, environment and development in Central Owambo, Namibia. Desert Research Foundation of Namibia, Windhoek, Namibia.

McCord, T. B., Hansen, G. B., Buratti, B. J., Clark, R. N., Cruikshank, D. P., D’Aversa, E., Griffith, C. A., Baines, K. H., Brown, R. H., Dalle Ore, C. M., Filacchione, G., Formisano, V., Hibbitts, C. A., Jaumann, R., Lunine, J. I., Nelson, R. M., Sotin, C., \& the Cassini VIMS Team (2006). Composition of Titan's surface from Cassini VIMS. Planetary and Space Science, 54, 1524 -1539 .

McCord, T. B., Hayne, P., Combes, J., Hansen, G. B., Rodriguez, S., Le Mouélic, S., Baines, K. H., Buratti, B. J., Sotin, C., Nicholson, P., Jaumann, R., \& Nelson, R. a. (2008). Titan's surface: Search for spectral diversity and composition using the Cassini VIMS investigation. Icarus, 194, $212-242$
McEwen, A., Turtle, E., Perry, J., Dawson, D., Fussner, S., Collins, G., Porco, C., Johnson, T., \& Soderblom, L. (2005). Mapping and monitoring the surface of Titan. Bulletin of the American Astronomical Society, 37, 739. DPS Meeting 37.

Mendelsohn, J., Jarvis, A., Roberts, C., \& Robertson, T. (2002). Atlas of Namibia. A portrait of the land and its people. David Phlips Publishers. 200pp

Miller, R. M. (1997). Chapter 11: The Owambo basin of northern Namibia. In R. C. Selley (Ed.), African Basins (pp. 237 - 268). Elsevier volume 3 of Sedimentary Basins of the World.

Miller, R. M., Pickford, M., \& Senut, B. (2010). The geology, palaeontology and evolution of the Etosha Pan, Namibia: Implications for terminal Kalahari deposition. South African Journal of Geology, 113, 307 - 334.

Mitchell, J. L., Pierrehumbert, R. T., Frierson, D. M., \& Caballero, R. (2009). The impact of methane thermodynamics on seasonal convection and circulation in a model Titan atmosphere. Icarus, 203, 250 - 264.

Mitri, G., Showman, A. P., Lunine, J. I., \& Lorenz, R. D. (2007). Hydrocarbon lakes on Titan. Icarus, 186, $385-394$

Moriconi, M. L., Lunine, J. I., Adriani, A., D’Aversa, E., Negrao, A., Filacchione, G., \& Coradini, A. (2010). Characterization of Titan's Ontario Lacus region from Cassini/VIMS observations. Icarus, 210, 823 - 831.

Niemann, H., Atreya, S., Demick, J., Gautier, D., Haberman, J., Harpold, D., Kasprzak, W., Lunine, J., Owen, T., \& Raulin, F. (2010). Composition of Titan's lower atmosphere and simple surface volatiles as measured by the Cassini-Huygens probe gas chromatograph mass spectrometer experiment. Journal of Geophysical Research, 115, E12006.

Niemann, H. B., Atreya, S. K., Bauer, S. J., Carignan, G. R., Demick, J. E., Frost, R. L., Gautier, D., Haberman, J. A., Harpold, D. N., Hunten, D. M., Israel, G., Lunine, J. I., Kasprzak, W. T., Owen, T. C., Paulkovich, M., Raulin, F., Raaen, E., \& Way, S. H. (2005). The abundances of constituents of Titan's atmosphere from the GCMS instrument on the Huygens probe. Nature, 438, 779 - 784 .

Paillou, P., Crapeau, M., Elachi, C., Wall, S., \& Encrenaz, P. (2006). Models of synthetic aperture radar backscattering for bright flows and dark spots on Titan. Journal of Geophysical Research, 111, E11011.

Paillou, P., Lunine, J., Ruffié, G., Encrenaz, P., Wall, S., Lorenz, R., \& Janssen, M. (2008a). Microwave dielectric constant of Titan-relevant materials. Geophysical Research Letters, 35, L18202.

Paillou, P., Mitchell, K., Wall, S., Ruffié, G., Wood, C., Lorenz, R., Stofan, E., Lunine, J., Lopes, R., \& Encrenaz, P. (2008b). Microwave dielectric constant of liquid hydrocarbons: Application to the depth estimation of Titan's lakes. Geophysical Research Letters, 35, L05202.

Perry, J., McEwen, A., Fussner, S., Turtle, E., West, R., Porco, C., Knowles, B., Dawson, D., \& the Cassini ISS Team (2005). Processing ISS images of Titan's surface. In Lunar and planetary Science XXXVI (p. 2312).

Porco, C. C., Baker, E., Barbara, J., Beurle, K., Brahic, A., Burns, J. A., Charnoz, S., Cooper, N., Dawson, D. D., Del Genio, A., Denk, T., Dones, L., Dyudina, U., Evans, M. W., Fussner, S., Giese, B., Grazier, K., Helfenstein, P., Ingersoll, A. P., Jacobson, R. A., Johnson, T. V., McEwen, A., Murray, C. D., Neukum, G., Owen, W. M., Perry, J., Roatsch, T., Spitale, J., Squyres, S., Thomas, P., Tiscareno, M., Turtle, E. P., Vasavada, A. R., Veverka, J., Wagner, R., \& West, R. (2005). Imaging of Titan from the Cassini spacecraft. Nature, 434, $159-168$.

Porco, C. C., West, R. A., Squyres, S., McEwen, A., Thomas, P., Murray, C. D., Delgenio, A., Ingersoll, A. P., Johnson, T. V., Neukum, G., Veverka, J., Dones, L., Brahic, A., Burns, J. A., Haemmerle, V., Knowles, B., Dawson, D., Roatsch, T., Beurle, K., \& Owen, W. (2004). Cassini Imaging Science: Instrument Characteristics and Anticipated Scientific Investigations at Saturn. Space Science Reviews, 115, 363 - 497.

Rannou, P., Montmessin, F., Hourdin, F., \& Lebonnois, S. (2006). The latitudinal distribution of clouds on Titan. Science, 311, $201-205$.

Raulin, F. (2008). Planetary science: Organic lakes on Titan. Nature, 454, 587-589.

Richardson, J., Lorenz, R. D., \& McEwen, A. (2004). Titan's surface and rotation: New results from Voyager 1 images. Icarus, 170, 113 - 124

Rodriguez, S., Le Mouélic, S., Sotin, C., Clénet, H., Clark, R. N., Buratti, B. J., Brown, R. H., McCord, T. B., Nicholson, P. D., Baines, K. H., \& the VIMS Science team (2006). Cassini/VIMS hyperspectral observations of the Huygens landing site on Titan. Planetary and Space Science, 54, 1510 -1523 .

Rodriguez, S., Mouélic, S. L., Rannou, P., Sotin, C., Brown, R. H., Barnes, 
J. W., Griffith, C. A., Burgalat, J., Baines, K. H., Buratti, B. J., Clark, R. N., $\&$ Nicholson, P. D. (2011). Titan's cloud seasonal activity from winter to spring with Cassini/VIMS. Icarus, 216, 89-110.

Sen, A. D., Anicich, V. G., \& Arakelian, T. (1992). Dielectric constant of liquid alkanes and hydrocarbon mixtures. Journal of Physics D: Applied Physics, $25,516-521$.

Shaw, P. A., \& Thomas, S. G. (2000). Pans, playa and salt lakes. Arid zone Geomorphology, John Wiley and Sons (England).

Shepard, M. K., Campbell, B. A., Bulmer, M. H., Farr, T. G., Gaddis, L. R., \& Plaut, J. J. (2001). The roughness of natural terrain: A planetary and remote sensing perspective. Journal of Geophysical Research, 106, 32777-32795.

Shi, Z., \& Fung, K. B. (1994). A comparison of digital speckle filters. In IGARSS 94 (pp. 2129 - 2133). Proceedings of IGARSS.

Sotin, C., Jaumann, R., Buratti, B. J., Brown, R. H., Clark, R. N., Soderblom, L. A., Baines, K. H., Bellucci, G., Bibring, J.-P., Capaccioni, F., Cerroni, P., Combes, M., Coradini, A., Cruikshank, D. P., Drossart, P., Formisano, V., Langevin, Y., Matson, D. L., McCord, T. B., Nelson, R. M., Nicholson, P. D., Sicardy, B., Le Mouélic, S., Rodriguez, S., Stephan, K., \& Scholz, C. K. (2005). Release of volatiles from a possible cryovolcano from nearinfrared imaging of Titan. Nature, 435, 786-789.

Stiles, B. (2008). Cassini Radar Burst Ordered Data Product SIS, Version 2.0. Appendix D: ABDR Summary file (ASCII CSV), available at http://pds-imaging.jpl.nasa.gov/documentation/ Cassini_BODPSIS. PDF.

Stofan, E. R., Elachi, C., Lunine, J. I., Lorenz, R. D., Stiles, B., Mitchell, K. L., Ostro, S., Soderblom, L., Wood, C., Zebker, H., Wall, S., Janssen, M., Kirk, R., Lopes, R., Paganelli, F., Radebaugh, J., Wye, L., Anderson, Y., Allison, M., Boehmer, R., Callahan, P., Encrenaz, P., Flamini, E., Francescetti, G., Gim, Y., Hamilton, G., Hensley, S., Johnson, W. T. K., Kelleher, K., Muhleman, D., Paillou, P., Picardi, G., Posa, F., Roth, L., Seu, R., Shaffer, S., Vetrella, S., \& West, R. (2007). The lakes of Titan. Nature, 445, 61 - 64.

Tokano, T. (2008). Dune-forming winds on Titan and the influence of topography. Icarus, 194, $243-262$.

Tokano, T., Molina-Cuberos, G. J., Lammer, H., \& Stumptner, W. (2001). Modelling of thunderclouds and lightning generation on Titan. Planetary and Space Science, 49, 539 - 560.

Toon, O. B., McKay, C. P., Courtin, R., \& Ackerman, T. P. (1988). Methane rain on Titan. Icarus, 75, $255-284$

Turtle, E. P., Perry, J. E., Hayes, A. G., Lorenz, R. D., Barnes, J. W., McEwen, A. S., West, R. A., Del Genio, A. D., Barbara, J. M., Lunine, J. I., Schaller, E. L., Ray, T. L., Lopes, R. M. C., \& Stofan, E. R. (2011b). Rapid and extensive surface changes near Titan's equator: Evidence of April showers. Science, 331, 1414-1417.

Turtle, E. P., Perry, J. E., Hayes, A. G., \& McEwen, A. S. (2011a). Shoreline retreat at Titan's Ontario Lacus and Arrakis Planitia from Cassini Imaging Science Subsystem observations. Icarus, 212, 957 - 959.

Turtle, E. P., Perry, J. E., McEwen, A. S., DelGenio, A. D., Barbara, J., West, R. A., Dawson, D. D., \& Porco, C. C. (2009). Cassini imaging of Titan's high-latitude lakes, clouds, and south-polar surface changes. Geophysical Research Letters, 36, L02204.

UNEP (1992). World atlas of desertification. Edward Arnold, Sevenoaks, UK.

Vuitton, V., Yelle, V., \& Cui, J. (2008). Formation and distribution of benzene on Titan. Journal of Geophysical Research, 113, E05007.

Wall, S., Hayes, A., Bristow, C., Lorenz, R., Stofan, E., Lunine, J., Le Gall, A., Janssen, M., Lopes, R., Wye, L., Soderblom, L., Paillou, P., Aharonson, O., Zebker, H., Farr, T., Mitri, G., Kirk, R., Mtchell, K., Notarnicola, C., Casarano, D., \& Ventura, B. (2010). Active shoreline of Ontario Lacus, Titan: A morphological study of the lake and its surroundings. Geophysical Research Letters, 37, L05202.

West, R. A., \& Smith, P. H. (1991). Evidence for aggregate particles in the atmospheres of Titan and Jupiter. Icarus, 90, 330 - 333.

Wye, L. C., Zebker, H. A., \& Lorenz, R. D. (2009). Smoothness of Titan's Ontario Lacus: Constraints from Cassini RADAR specular reflexion data. Geophysical Research Letters, 36, L16201.

Zebker, H. A., Gim, Y., Callahan, P., Hensley, S., \& Lorenz, R. (2009). Analysis and interpretation of Cassini Titan radar altimeter echoes. Icarus, 200, 240 -255 . 